\title{
Reus, vila oberta. Els primers anys de la guerra de Separació
}

\author{
Manel Güell \\ Reial Societat Arqueològica Tarraconense \\ manelguell@acarn.cat
}

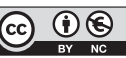

Rebut: juny de 2012

Acceptat: juliol de 2012

\section{Resum}

L'article exposa la difícil trajectòria d'una població gran durant la guerra de Separació. Els primers anys, Reus va trobar-se enmig d'una frontera militar d'una gran inestabilitat i va optar per no oferir resistència a l'ocupant i cooperar-hi, amb independència del bàndol de què es tractés. Alhora, va procurar mantenir les relacions amb els dos bàndols i proclamar la seva lleialtat a tots dos per separat. Reus va tenir una supervivència difícil, amenaçada per les inacabables aportacions als exèrcits (diners, armes, lleves, proveïments, treballadors) i sobretot pels allotjaments, que foren dels més durs de Catalunya. La vila, que hagué de suportar una despesa econòmica exorbitant, féu fallida i s'endeutà d'una manera exponencial i crònica. També va perdre bona part dels seus habitants. El cas de Reus és el cas de la lluita de les poblacions rurals per superar la crisi política i militar de mitjan segle XVII.

Paraules clau: Reus; guerra; exèrcit hispànic; bàndols; allotjaments; proveïments; despesa.

Resumen. Reus, villa abierta. Los primeros años de la guerra de Separación

El artículo expone la difícil trayectoria de una población grande durante la guerra de Separación. En los primeros años, Reus se halló en medio de una frontera militar de una gran inestabilidad, y optó por no ofrecer resistencia y cooperar con el ocupante, con independencia del bando de que se tratase. Al mismo tiempo procuró mantener las relaciones con ambos bandos y proclamar su lealtad a los dos por separado. Reus tuvo una supervivencia difícil, amenazada por las inacabables aportaciones a los ejércitos (dinero, armas, levas, provisiones, trabajadores) y sobre todo por los alojamientos, que fueron de los más duros de Cataluña. La villa, que soportó un gasto económico exorbitante, quebró y se endeudó de manera exponencial y crónica. También perdió buena parte de sus habitantes. El caso de Reus es el caso de la lucha de las poblaciones rurales por superar la crisis política y militar de mediados del siglo XVII.

Palabras clave: Reus; guerra; ejército hispánico; bandos; alojamientos; provisiones; gastos.

Abstract. Reus, an open village. The first years of the War of Separation

This article focuses on the difficult path of a large population during the War of Separation. In the early years, Reus was found in the middle of a military frontier of great instability, and chose not to resist and cooperate with the occupier, regardless of which side they were. At the same time, it sought to maintain relations with both sides and proclaim his loyalty towards the two. Reus had a difficult survival, threatened by the endless contributions (money, weapons, cams, 
provisioning, labour) and especially for the military billeting, which were the hardest of Catalonia. The village, with an exorbitant economic cost, broke into debt exponentially and chronic, and also lost many of its inhabitants. The case of Reus is the case of the struggle of rural populations to overcome the political and military crisis of the mid-seventeenth century.

Keywords: Reus; war; Spanish army; sides; military billeting; provisioning; cost.

\author{
Sumari \\ 1. La vila 4. El cost \\ 2. Jocs de lleialtats 5. Epíleg \\ 3. Els odiosos allotjaments Bibliografia
}

A mitjan juny de 1642, quan feia menys de dos anys que les tropes de Felip III havien envaït el Principat i menys d'un que havien superat un llarg i penós setge a Tarragona, un dietarista anònim de l'exèrcit hispànic que s'havia establert en aquesta ciutat com a capital de la zona «obedient», consignava:

No tratará el enemigo de venir s[obr]e esta plaça si no es teniendo not[ici]a se alla en estado de poderse llevar por ynterpresa, a causa de estar tan gastado este Campo de Tarrag[on]a y lugares de su contorno, que es ymposible conservarse ex[érci]to, ni aun mill hombres, si no es trayendo de fuera todos los víveres ${ }^{1}$.

Tenia raó, els francesos van trigar dos anys més a intentar-ho. Quan ho van fer, fou a través d'un assalt ràpid, violent, precipitat i fallit! Però allò que volem destacar de la citació és l'estreta vinculació entre el territori i l'operativitat d'un contingent armat nombrós. La logística dels exèrcits a mitjan segle XVII deixava molt a desitjar, i no seria fins a la centúria següent que es crearien intendències efectives que possibilitessin un manteniment sostingut dels soldats i, amb això, la consolidació dels exèrcits permanents. Així, doncs, al bell inici de la guerra de Separació, un exèrcit s'havia de mantenir a través de la cooperació, de grat o per força, del territori sobre el qual vivia. Aquesta realitat dibuixava una situació ben magra per a les poblacions civils properes, més encara si es trobaven a prop d'una frontera militar tan inestable i canviant com la que els primers anys de guerra hi va haver al Camp de Tarragona.

El cas de la vila de Reus és, en aquest sentit, molt interessant, ja que l'escenari geoestratègic s'ho valia. Després de la derrota a Montjuïc, els hispànics es tancaren a Tarragona, on van patir un terrible i dilatat setge (Güell, 2003), i no va ser fins després d'haver-lo llevat que les tropes de Felip III tornaven a escampar-se

1. Diario de las guerras de Cataluña por los años 1640, 1641 y 42 [= Diario...]. Biblioteca Nacional de España [= BNE], Manuscritos, reg. 2.337, f. 361v. Aquesta obra, mig inèdita, consta escrita per Antonio Pellicer, si bé nosaltres ja en vam descartar aquesta autoria (Güell, en premsa). 
pel Camp de Tarragona i van recuperar terreny. Dins d'aquest context, qualsevol fet d'armes podia trastocar la situació a favor dels uns o dels altres (Montjuïc, el primer setge de Tarragona, la batalla de Paret Delgada, la desfeta de Sant Celoni, el front de Ponent, el segon setge de Tarragona, etc.) i fer-los avançar o retrocedir, però, en definitiva, mantenint una frontera militar que, amb diverses variacions, creuava el Camp de Tarragona per dalt i per baix.

Aquesta fluctuació constant donà com a resultat que les viles d'aquesta zona, especialment Reus, passessin d'unes mans a les altres contínuament, en un fenomen prou típic d'aquella guerra que s'ha estudiat, per exemple recentment, en el cas d'Àger (Cristòfol, 2011). Al llarg de la contesa, aquesta vila ponentina canvià de domini fins a cinc vegades. Tanmateix, el cas de Reus és més difícil de precisar, perquè era una vila oberta, mai no va oferir resistència i es reté, s'entregà, pactà i/o col-laborà immediatament amb qualsevol força militar que se li plantava al davant, fos del color que fos, a voltes en un descarat doble joc que procurarem destapar al llarg d'aquest article.

\section{La vila}

El poblament gaudeix d'una situació geogràfica privilegiada. La vila es troba assentada als últims contraforts de la serralada pradenca i ocupa una zona de confluència important al bell mig de la plana del Camp de Tarragona, limitada per les muntanyes de Prades i la mar. Al llarg del temps, sabé connectar una notable xarxa de vies de comunicació que la féu punt de referència de bona part de les poblacions de la comarca, i no menys de les del voltant: la Conca de Barberà, el Priorat i la Ribera d'Ebre (Rovira i Gómez et al., 1982: 174). Malgrat la seva condició de vila, Reus era una de les poblacions més grans del Camp de Tarragona, amb un nombre d'habitants similar als de la capital tarragonina i Valls. D'acord amb el càlcul que hem efectuat de la taxa de natalitat corresponent al quinquenni previ a la guerra (1635-1640), se li podien estimar uns 5.120 residents (amb sengles taxes de fills de pares incògnits - 0,87\%— i de bessonades $-0,48 \%$ - sensiblement baixes ${ }^{2}$, quan a Tarragona hi havia 5.155 habitants i a Valls, 5.595 (Güell, 1996: 249). En entrar a la dècada de 1640, veurem baixar totes aquestes xifres i tots aquests percentatges.

La privilegiada situació a la qual ens referíem més amunt dotà la vila d'un ampli rerepaís que li va permetre l'adquisició, la comercialització i la concentració dels estocs i els excedents agrícoles i industrials, amb una interessant sortida al mar per la propera platja de Salou, mal que il·legal i d'una competència fraudulenta pregona amb la capital tarragonina. De fet, al segle XVIII, Reus es va convertir en la capital de l'aiguardent, atès que n'aglutinava la major part de la producció de

2. Ens basem en l'únic estudi d'abast comarcal que ha calculat en tants per cent els fills de pares incògnits, a l'època moderna, a la Conca de Barberà (Gual, 1993: 152-199) i que, calculat localitat per localitat, dóna un percentatge general de 1'1,18\%. Quant als parts múltiples, Tarragona, Cabra del Camp, Rocafort de Queralt i altres poblacions de la Conca de Barberà compartien, a l'època moderna, una taxa molt similar del 0,69\% (Güell, 2011: 189). 
l'interior i li donava sortida per Salou a tot Europa (Rovira i Gómez et al., 1982, VII: 176; Jordà i Pujals, 1983; Andreu, 1986; Morell, 1986; Segarra, 1988; Morell, 1993; Segarra, 1994). Això ens porta al seu indiscutible lideratge (juntament amb Valls i Alcover) dins de la Comuna del Camp (Fort, 1975), de manera que el seu parer era sovint el pes que feia decantar la balança cap a un costat o cap a l'altre. Quan, l'any 1639, Reus envià una companyia dels seus veïns al setge de Salses, s'integraren en el contingent uns 45 homes més que corresponien a les poblacions d'Alforja, Almoster, les Borges del Camp, Castellvell, Mascalbó, Montbrió, Mont-roig del Camp, el Morell, la Pobla de Montornès, Riudoms, Vila-seca, Vinyols i els Arcs, el priorat de la Cartoixa i la baronia d'Escornalbou ${ }^{3}$. No hi ha dubte que aquests pobles constituien el rerepaís reusenc.

Ja al segle XVII, Reus s'havia convertit en l'anticapital del Camp de Tarragona, un contrapès que consolidà la sempiterna rivalitat existent amb la capital (AADD, 1990). Aquest poder adquisitiu i de captació de recursos, la influència que projectava sobre les comarques i la contraposició amb la capital tarragonina, seu consolidada dels hispànics, van fer de Reus un objectiu cobejat tant per un bàndol com per l'altre. Les autoritats de tots dos maldaven, almenys al llarg dels primers anys de la contesa, per atraure'n el favor i la col-laboració en exclusiva.

Els reusencs s'aprofitaren d'aquesta situació i feren el possible per nedar i guardar la roba, o sigui, navegar per les turbulentes aigües de la guerra i procurar sortir-ne indemnes. Però la guerra és un monstre massa voraç i, si bé evitaren el saqueig (d'esquitllentes), no pogueren fer el mateix amb les quantioses contribucions i aportacions als exèrcits, i patiren ferotges allotjaments anuals de soldats.

\section{Joc de lleialtats}

Durant la campanya per la recuperació de la fortalesa de Salses (Serra, 1988; Güell, 2008: 135-176), l'any 1639, Reus complí enviant-hi una companyia de 113 homes, que, al llarg de la campanya, augmentà amb un segon enviament de 55 més, i els últims dies amb un esforç final d'una vintena, amb jurat, consellers i vilatants destacats de l'oligarquia local (Joan Espuny, Pau Miró, el Dr. Cosme Anguera, Pere Baldrich, Pere Clariana, Joan Pàmies Mascabrés, etc., noms que no tardarien a ser constants en la documentació pels càrrecs ocupats) (Bofarull, 1846: 16) ${ }^{4}$. Amb aquests 189 milicians, Reus es constituïa com la segona població del Camp de Tarragona en aportació d'efectius humans al Rosselló, després de la ciutat de Tarragona, que la doblà (Güell, 2008: 172). Algun d'aquests milicians féu el servei destacat ben a prop del virrei comte de Santa Coloma, com ara

3. Arxiu Comarcal del Baix Camp [= ACBC], Fons municipal de Reus, lligall «Guerras contra Francia», 1542-1704, reg. 1755/1759 [= «Guerras contra Francia»], núm. 51.

4. Bofarull es va equivocar força, ja que datà l'expedició erròniament. La va situar al 27 de desembre de 1640 i no de 1639 —en el calendari del Dia de la Nativitat, que llavors imperava, l'any començava el 25 de desembre i no l'1 de gener, per tant, el seu 27 de desembre de 1640 és per a nosaltres el 27 de desembre de 1639. Els esforços per donar una explicació plausible a aquesta expedició i encabir-la en el context d'un any més tard són còmics, si no fan plorar... 
Pere de Granada, que s'integrà en la companyia de nobles que li feia de guàrdia de corps ${ }^{5}$. A més dels milicians, els reusencs hi enviaren igualment una desena de cavalcadures, que, a principis de febrer de 1640 (Salses capitulà el dia 6 de gener), encara no havien retornat ${ }^{6}$.

\section{Els revolucionaris}

Entre maig i juny de 1640, el país fou sacsejat de dalt a baix per uns fets revolucionaris que el divorciaren de la monarquia hispànica. Ja el 22 de maig, s'havia produit un motí de segadors a través del qual foren alliberats de les presons el diputat Francesc de Tamarit i els consellers Vergòs i Lleonard Serra. Una setmana abans del Corpus de Sang (6 de juny), el doctor Josep Queralt escrivia als jurats de Reus recomanant fortament Jacint Vilosa (Florensa i Güell, 2005: 95-98), instant-los a obeir les seves ordres i a col-laborar-hi estretament, àdhuc amb enganys, ja que hi afegia «perq[uè] així o a resolt lo Real Consell [...] ${ }^{7}$, quan sabem que les úniques facultats que tenia Vilosa li foren dades pel subcollector de la Cambra Apostòlica.

L'engany serà una constant de les autoritats de Barcelona per assegurar-se la col-laboració no únicament de Reus, sinó també de tot el Camp de Tarragona (Florensa i Güell, 2005: 114-119). Si ens limitem estrictament al cas de Reus, direm que, amb l'amenaça del perill d'una esquadra francoholandesa de 40 vaixells que amenaçava de desembarcar precisament a la costa tarragonina, el diputat reial Miquel Joan Quintana els exigia, a través dels cònsols de Tarragona, recompte d'armes i de gent mobilitzable, i que tinguessin la milícia armada i previnguda. El 29 d'agost de 1640, Vilosa els advertia, des de Riudecanyes, que, per l'estret de Gibraltar, havien passat 160 vaixells enemics disposats a arribar per la part de Salou i que s'havia d'acudir a defensar la pàtria i posar-se al servei del rei $^{8}$. Les 200 veles que amenaçaven de caure sobre la costa es van quedar en quatre (ja no de francesos, sinó de turcs) els primers dies de setembre, quan Joan de Tamarit Lladernosa era a Vila-seca i els jurats del lloc demanaven gent armada a Reus ${ }^{9}$. El dia 11 següent, Vilosa, des de Constantí, seguia mantenint l'engany i instava els jurats reusencs a tenir la milícia preparada, perquè tot el país estava en situació d'alerta esperant la invasió d' «alguns enemichs del Rey n[ostr]e

5. Archives Departamentales des Pirenées Orientales [= ADPO], 1B, reg. 390, núm. 19. Granada rebé l'extremunció la nit del 24 d'agost de 1645 i va ser enterrat l'endemà. Arxiu Històric Arxidiocesà. Tarragona [= AHA], Parròquia de la Prioral de Sant Pere de Reus, òbits, 1639-1667, capsa 58, núm. 123 , f. 83v.

6. ACBC, Fons municipal de Reus, Correspondència, 1601-1643, reg. 509/2, camisa 1640, núm. 316.

7. Dr. Josep Queralt als jurats de Reus, Barcelona-Reus, 1 de juny de 1640. ACBC, Fons municipal de Reus, Correspondència, 1601-1643, reg. 509/2, camisa 1640, núm. 320.

8. Cònsols de Tarragona als jurats de Reus, Tarragona-Reus, 5 d'agost de 1640. ACBC, Fons municipal de Reus, Correspondència, 1601-1643, reg. 509/2, camisa 1640, núm. 299 i 304 (13 d'agost), Acords, 1636-1673, reg. 12, f. 112-114 (Florensa i Güell, 2005: 117).

9. Jurats de Vila-seca als jurats de Reus, Vila-seca-Reus, 4 de setembre de 1640. ACBC, Fons municipal de Reus, Correspondència, 1601-1643, reg. 509/2, camisa 1640, núm. 315. 
S[enyo]r». Com a conseqüència, els reusencs allistaren una companyia local de 50 homes $^{10}$. En una data inconcreta, el mateix Vilosa ajustà una unió a Reus «A efecte de perseguir, espellir, capturar y extirpar los lladres, homiçides, assasinos y altres facinerosos de la p[rese]nt vila de Reus» ${ }^{11}$, la qual no cal ser gaire llest per suposar que no seria sinó una altra enganyifa per tenir ben disposada la milícia local.

El dia 25, Joan de Tamarit els manà enviar gent armada, «encara que sia ab xispes llargues», a Riudoms, on concentrava forces per remetre al diputat militar, pendent d'entrar a Tortosa, i, dos dies més tard, els exigia els 50 homes allistats, que n'acreixessin el nombre i en nomenessin pagador i dos caps d'esquadra ${ }^{12}$.

\section{Salou}

A principis d'octubre de 1640, aparegué en escena un nou personatge, el comte de Savallà (Francesc de Boixadors de Rocabertí, senyor de Vallmoll, Bràfim i Nulles -Florensa i Güell, 2005: 95-96), cap militar de l'exèrcit català que havia d'aturar la invasió hispànica, primer, a Tortosa i, després, a Cambrils. Llavors ja no hi havia marge per a enganys: l'enemic eren els castellans, que pujaven pel sud arrasant-ho tot a sang $\mathrm{i}$ a foc. L'estratègia dels reusencs va ser contemporitzar amb les demandes d'enviament de gent i abocar tot l'esforç de la vila en la fortalesa de Salou, que serviria d'escut a les demandes d'enviament de gent. Això fou així en ocasió de sengles cartes escrites per reclamar soldats, una del comte de Savallà, per a Tortosa, i l'altre dels jurats de Vila-seca, per guardar-se de la dotzena de galeres mores que s'havien divisat apropant-se i que ja havien capturat algunes barques de pescadors. El dilema era fàcil de resoldre: atendrien la demanda d'ajut dels vila-secans perquè «està tan prop y és major lo perill» ${ }^{13}$.

Reus es volcà en la fortalesa de Salou. Hi va enviar homes per fer-hi de guardes, treballadors (manobres, fusters, picapedrers, mestres de casa, jornalers), carros de transport, etc., tot pagat puntualment, com acrediten la gran quantitat de rebuts que se'n conserven. El 4 d'octubre, Tamarit Lladernosa els reclamava el miler de lliures que havien ofert pel finançament de les obres de la fortalesa ${ }^{14}$. Dos dies més tard, Savallà es plantà a Reus, a fi de demanar més gent per fortificar el coll de Balaguer, gent que el Consell no volgué donar-li, al-legant que la resta de poblacions de la vegueria «fins vuy no la an donada». En canvi, envià

10. Jacint Vilosa als jurats de Reus, Constantí-Reus, 11 de setembre de 1640. ACBC, Fons municipal de Reus, Correspondència, 1601-1643, reg. 509/2, camisa 1640, núm. 295 i Acords, 16361673, reg. 12, f. 156.

11. ACBC, «Guerras contra Francia», lligall 1542-1640, núm. 53.

12. Joan de Tamarit Lladernosa als jurats de Reus, Riudoms-Reus, 25 de setembre de 1640. ACBC, Fons municipal de Reus, Correspondència, 1601-1643, reg. 509/2, camisa 1640, núm. 310 i Acords, 1636-1673, reg. 12, f. 158.

13. ACBC, Fons municipal de Reus, Acords, 1636-1673, reg. 12, f. 160, i Jurats de Vila-seca als jurats de Reus, Vila-seca-Reus, 4 d'octubre de 1640, Correspondència, 1601-1643, reg. 509/2, núm. 301 i 325.

14. Joan de Tamarit Lladernosa als jurats de Reus, Tarragona-Reus, 4 d'octubre de 1640. ACBC, Fons municipal de Reus, Correspondència, 1601-1643, reg. 509/2, camisa 1640, núm. 312. 
50 homes i 500 lliures a la fàbrica de Salou i sindicaren quatre prohoms perquè venguessin censals i obtinguessin líquid per afrontar tanta despesa ${ }^{15}$.

La destinació salouenca, atesa la delicada situació, no semblava que fos del grat de ningú. Els jurats hagueren d'enviar els 50 homes en tres torns i permetre que els designats presentessin substitut i, si es negaven a fer totes dues coses, se'ls imposava una multa de 3 lliures, aplicadores, per descomptat, a la fàbrica de la fortalesa. Per tal de fer-ho complir, nomenaren un clavari que s'encarregués de cobrar els renitents, amb un salari de 2 sous per lliura recaptada. De seguida es mostrà el desànim en la gent tramesa a Salou, que anava i venia sense fer res, cosa que obligà el Consell a enviar-hi 20 treballadors ben pagats (a través d'un tall a la població) que s'hi estiguessin una setmana seguida ${ }^{16}$.

Però l'enemic castellà avançava ràpid, el 25 de novembre entrava a Tortosa $\mathrm{i}$ el 27 perpetrava un brutal i desproporcionat assalt sobre Xerta que va sotragar Barcelona. A les desesperades reclamacions d'ajut de Savallà el 29 de novembre, el Consell de Reus resolgué «que no se alçe sometent general per ara», i va donar, a tot estirar, 25 o 30 homes dels 60 que tenia allistats ${ }^{17}$. Quan, dotze dies més tard, el marquès de Los Vélez estava sobre el coll de Balaguer, Savallà ja no va demanar, va exigir, i a Reus tocaren les campanes del sometent amb ordres «que vage hun home de cada casa de tota la vila, ab la prestesa pussible y que.s pose la pena que diuen las cartillas, que és pena de la vida» ${ }^{18}$.

\section{Cambrils}

Superat, amb la matança corresponent, l'obstacle del coll de Balaguer, l'exèrcit hispànic entrava al Camp de Tarragona i posava setge a Cambrils, plaça d'armes catalana, on s'havien tancat totes les milícies aixecades. També la de Reus. Malgrat el fervor patriòtic que, en un primer moment, van poder experimentar (en una reunió de la Comuna del Camp, el síndic reusenc Josep Pedret «pronuncià un discurs, roent de patriotisme, en el qual advocà per l'alçament del Camp davant l'exèrcit castellà» —Alentorn, 1931: 31-32), la crua realitat els féu tocar, ben aviat, de peus a terra.

El dia 13 de desembre de 1640, mentre la cavalleria d'Álvaro de Quiñones massacrava 800 catalans emboscats als afores de Cambrils, la del duc de San Jorge es plantava davant la vila de Reus i l'obligava a rendir-se. San Jorge oferia totes les seguretats, però, si no es rendien, els faria «passar per lo rigor de la Guerra». Els exemples de Xerta, el Perelló, el coll de Balaguer i l'Hospitalet no donaven marge a dubtar sobre l'abast d'aquest «rigor». Els diputats els prometien socors, però no especificaven quins serien ni quan arribarien. Així les coses, els reusencs van plantejar-se tres opcions: 1) retre's als hispànics; 2) defensar-se dels hispànics, o 3)

15. ACBC, Fons municipal de Reus, Acords, 1636-1673, reg. 12, f. 162.

16. ACBC, Fons municipal de Reus, Acords, 1636-1673, reg. 12, f. 163-164.

17. ACBC, Fons municipal de Reus, Acords, 1636-1673, reg. 12, f. 168 (Bofarull, 1846: II, 15; Florensa i Güell, 2005: 187).

18. ACBC, Fons municipal de Reus, Acords, 1636-1673, reg. 12, f. 172 (Bofarull, 1846: II, 15; Maristany, 2003: 175). 
abandonar la vila (opció que ja havien executat poblacions com ara Mont-roig, Montbrió del Camp o Riudoms —Diario: 3v. i 7v.). Tractant-se d'una decisió molt crucial, els jurats van convocar consell general de la vila per a l'endemà, dia 14, on s'explicà que havien demanat ajut a un mossur que comandava 4.000 soldats a la Selva, el qual se'n dessentengué. Desenganyats del suport català i tenint en compte com (de malament) anaven les coses a Cambrils (els reusencs devien estar informats que la plaça era a punt de caure) i que allí tenien 700 o 800 homes naturals de la vila, «Fonch determinat per lo Consell General, sens oir que contradís algú, que.ns rendissem al Rey, puys veyem que no tenim resistència» ${ }^{19}$.

De seguida van enviar a suplicar per la vida dels 800 reusencs que eren dins de Cambrils. La resolució del consell general degué ser a primera hora del matí, perquè, a les dues del migdia, els jurats reusencs eren postrant-se als peus del marquès de Los Vélez. Va ser la primera població que ho va fer («y asta aora no se a dado otro lugar»-Diario, 6), circumstància que les cartes de recomanació i els memorials posteriors van explotar amb lletres d'or. Darrere de Reus, van venir els representants de Vila-seca de Solcina i de la Selva del Camp. El marquès de Los Vélez va acceptar la prestació d'obediència de Reus i va complir la seva paraula. L'endemà, Cambrils es rendia i un altre dia (16 de desembre), a primera hora, sortien els defensors desarmats, que els hispànics anaren separant d'acord amb la vila d'on provenien, «mandó [el marquès de Torrecuso] abrir un postigo y fué apartando a un lado los vecinos de Reus, lugar que el sávado vino a la ovediencia, y al otro lado diversos lugares». Una separació providencial, per tal com, tot seguit, per malícia o per error, els soldats hispànics carregaren contra la resta dels rendits i en feren el més sonat carnatge de tota aquella guerra (Florensa i Güell, 2005: 204-206).

L'endemà d'aquesta nova massacre, la meitat de la cavalleria hispànica, que estava allotjada a Riudoms, passà a Reus «donde fuimos vien reçividos», fins a l'últim dia del mes, que partí camí de Barcelona. A més, van enviar cinc càrregues i mitja de vi a Cambrils i van proveir de llenya tots els cossos de guàrdia ${ }^{20}$. La notícia de la rendició reusenca i l'estreta col-laboració amb el marquès de Los Vélez només necessità dos dies per arribar a Barcelona, on va causar un fort impacte (Maristany, 2003: 176-177). Els diputats declararen enemigues de la pàtria les viles ocupades i decidiren revenjar-se especialment de la de Reus. Així, van confiscar diversos béns mobles a les cases dels reusencs residents a la capital catalana (síndics, botiguers i paraires — Sebastià Cot, Joan Francesc Gualdo, Joan Serra i alguns més), per un valor de 65 lliures. També tot el crèdit que tenien a la taula de canvis, cosa que pujà a quasi 4.353 lliures $^{21}$.

Després de Montjuïc, Reus allotjà més de 2.000 militars hispànics durant setmanes, fins als darrers dies d'abril (el 27 deixaven la vila els dos terços que hi eren, camí de Constantí, i dos dies més tard, ho feia tota la cavalleria que quedava -Diario: 54v. i 57).

19. ACBC, Fons municipal de Reus, Acords, 1636-1673, reg. 12, f. 174 i 179 (Bofarull, 1846: II, 16; Alentorn, 1931: 35; Maristany, 2003: 176).

20. ACBC, «Guerras contra Francia», s/n.

21. ACBC, «Guerras contra Francia», lligall 1542-1640, núm. 51. 


\section{El setge de Tarragona (maig-agost de 1641)}

Després de la victòria a Montjuïc (26 de gener de 1641), Reus s'alliberava dels hispànics i, és clar, tornava a caure dins de l'òrbita contrària. El 2 de maig següent, Francesc Cabanyes els prohibia que deixessin entrar a la vila cap miquelet «p[er] ocasió de q[ue] si entraven és sert sucseiria algun strago», i, si venia l'enemic, que s'hi resistissin, perquè ells acudirien al socors. Finalment, els demanava els cavalls, la roba, els bagatges, el blat i pertrets militars que s'haguessin deixat els hispànics. De tot això, n'havien de fer un memorial i trametreli $^{22}$. En aquella data, alguns soldats francesos ja s'allotjaven a Reus. L'autor del Diario diu que així ho van corroborar una quinzena de cavalls escollits que s'hi atansaren aquell dia, i s'assabentaren, a més, que havien occit dos tinents i alguns soldats que havien quedat malalts. Desenganyat, acabava sentenciant: «se bé lo que ay que fiar d.esta gente». No havien estat els reusencs, sino una trepa de miquelets que, malgrat els advertiments de Cabanyes, entraren a la vila «con consentimiento de los del lugar y se llevaron catorçe o quinçe soldados con sus caballos, y ayer volvieron a buscar por las cassas los soldados que avia enfermos y degollaron veynte y dos» (Diario: 60-60v. i 61v.) i se li van haver de donar 100 lliures al capità Negre «que promaté que no saguejaria la vila» ${ }^{23}$. El 9 de maig de 1641 , els jurats i prohoms reusencs sortien a rebre l'almirall Sourdis i els exèrcits francès i català i els entregaren les claus de la vila (Bofarull, 1846, II: 18).

Reus, igual que moltes altres poblacions, havia passat de ser lleial a Felip III a ser-ne a la Diputació del General, per tornar a l'obediència de l'Àustria després de Cambrils i tornar a la de la Diputació després de Montjuïc. Més endavant, encara veurem més canvis de bàndol.

Al llarg del setge, la documentació il-lustra profusament com les autoritats catalanes van requerir tota mena de recursos als reusencs ${ }^{24}$ : diners, bastiments, vi, treballadors (terrelloners, fusters, mestres de casa), carros de transport, carbó, calç viva (per enterrar els morts), adobament d'armes, palla per a la cavalleria i manteniment d'un hospital militar ben dotat. Van aprofitar aleshores per fer-los liquidar les 417 lliures que devien als diputats per adquirir la partida de 32 arcabussos i 5 mosquets «que foren los darrés que tenia la Deputació en aquella ocasió», i que comprà Pau Ferran a mitjan 1640, quan la revolució segadora sacsejava tot el país ${ }^{25}$.

També els van fer contribuir amb lleves de soldats, ja que van haver de trametre al setge una companyia pagada i proveïda de munició per a la vila, del qual n'era l'enllaç l'alferes Rafel Llanes, una companyia lluïda que feia goig, almenys en va fer als diputats i a Josep de Margarit, els quals quedaren «folgats moltís-

22. ACBC, Fons municipal de Reus, Correspondència, 1601-1643, reg. 509/2, camisa 1641.

23. ACBC, Fons municipal de Reus, Acords, 1636-1673, reg. 12, f. 208; «Guerras contra Francia», 1ligall, 1641-1704, s/n. La informació es complementa amb un rebut que presentà Pere Marca, qui negocià la composició.

24. Diverses cartes als jurats de Reus, de Francesc de Tamarit, Cabanyes o el conseller de Barcelona Rossell, memorials de comptes. ACBC, Fons municipal de Reus, Correspondència, 1601-1643, reg. 509/2, camisa 1641; «Guerras contra Francia».

25. En parlava temps després Josep d'Urrea als jurats de Reus, Barcelona-Reus, 19 de setembre de 1643. ACBC, Fons municipal de Reus, Correspondència, 1643-1691, reg. 1.897. 
sim», al comprovar «que no $n \cdot i$ ha ninguna de altras tan bona com és la nostra» ${ }^{26}$. Els mateixos veïns que feia un parell de mesos havien servit els hispànics, aleshores els disparaven trets! La companyia era de 100 soldats i, pels rebuts de socors que se'ls pagava (60 lliures diàries), podem suposar que fou llevada el 28 de juny i que encara estava operativa el 18 de desembre ${ }^{27}$. A mitjan juliol, faltaven molts efectius i un Margarit menys «folgat» manava als jurats de reposar-los com fos, «y així, quant enlloch dels fugits no troben soldats, los trauran a rodolins, y en això no $\cdot y$ haja falta» ${ }^{28}$. Un compte de l'aportació que rebia cada soldat de la companyia reusenca, de 26 d'agost de 1641, revela un total de 48 efectius! ${ }^{29}$.

\section{Statu quo al Camp de Tarragona}

Però el setge a Tarragona no va reeixir. La plaça va ser socorreguda per l'armada hispànica el 19 d'agost i, dos dies més tard, La Mothe decidí plegar. Ara els vents bufaven per l'altre costat, i els partidaris de Felip III, que no devien ser pocs a Reus, es començaren a fer notar. A les nits de diumenge i dilluns de la segona setmana de setembre de 1641, passada la mitjanit, es va poder sentir bé pels carrers de Reus qui cridava: « $i$ Víctor y viva el rey de España, y al traidor que otra cossa se atreviera a decir, le hemos de quemar la cassa!» (Diario: 179v.).

Sembla que s'hi atansaren els hispànics $i$, ultra de dir que no els van rebre, tampoc sembla que se'ls espolsessin de sobre, almenys tan enèrgicament com haguessin esperat les autoritats catalanes. Així, el 18 d'octubre de 1641, els tres jurats de la vila van haver de comparèixer, instats formalment per un comissari, davant de Pere Joan Rossell, conseller terç de Barcelona, a Valls. Allí van haver de respondre per la «poca diligènçia ab expelir» els castellans $i$, malgrat les raons que van argüir, els va caure multa a cada un de 2.000 ducats, pagadors sens falta el dimarts següent en presència seva. Un fet providencial sortí llavors a favor dels reusencs. Els hispànics tornaren a atansar-se (de fet, ho feien diàriament) i, el 19 d'octubre, els jurats feren tocar l'alarma i acudir tothom armat. Van fer valdre aquest mèrit per comunicar a Barcelona «que cada dia estem ab estes inquietuts de venir soldats, i que los soldats que la provínsia té en la p[rese]nt vila, ni los naturals y gent del poble són bastants a resistir a les tropes de cavalls que venen cada dia $\mathrm{i}$ que se suplique a dit $\mathrm{S}[\mathrm{enyo}] \mathrm{r}$ qu ens envie socorro $\mathrm{p}$ [er] a resistir en cas vinguen soldats castellans, o que no·ns culpa si acás sucseïe lo contrari, eo que veja de la millor manera nos avem de governar» ${ }^{30}$. No eren quimeres. Cer-

26. Rafel Llanes als jurats de Reus. Constantí-Reus, 7 de juny de 1641. ACBC, Fons municipal de Reus, Correspondència, 1601-1643, reg. 509/2, camisa 1641.

27. ACBC, «Guerras contra Francia», lligall de 1641-1704.

28. Josep de Margarit als jurats de Reus. Constantí-Reus, 19 de juliol de 1641. ACBC, Fons municipal de Reus, Correspondència, 1601-1643, reg. 509/2, camisa 1641, núm. 326. Els jurats no s'hi posaren fins un mes després. Acords, 1636-1673, reg. 12, f. 190.

29. ACBC, «Guerras contra Francia», lligall 1641-1704.

30. ACBC, Fons municipal de Reus, Acords, 1636-1673, reg. 12, f. 198-199. Els jurats eren Rafel Fortuny, Antoni Nogués i Joan Salvat. Amb ells anaren a Valls alguns consistorials: el Dr. Cosme Anguera (del Consell Secret), Joan Gras, Joan Pàmies i Pere Miret. 
tament, es registra activitat aquells dies prop de Reus: el 21 d'octubre, els hispànics feren caure l'enemic en un parany, i tres dies més tard esquivaven un altre atac dels francesos a la sortida de la vila (Diario: 206v. i 208).

A finals d'octubre, la tensió amb les autoritats franceses era extrema. Segons el Diario, els reusencs no hi van voler contribuir amb una quantitat de diners i els francesos baixaren amb quatre peces d'artilleria «a destruilles», amb l'excusa que s'havien assabentat que els jurats volien prestar obediència a Felip III a Tarragona. Els francesos convertiren Reus en caserna, des de la qual podien operar per tota la comarca i no es descartava que artillessin la vila. L'entrada dels francesos no va ser gens pacífica, tenien la intenció de represaliar i, segons uns cavallers hispànics que s'hi atansaren el 27 d'octubre, «avia mucho umo en Reus, y se uya disparar, por donde juzgan deven de batirla o quemarla». Efectivament, l'endemà mateix, aparegueren a Tarragona «seis personas y gente común que procuraron contradeçir el alojam[ien]to del enemigo, que como se allavan sin fuerças y él trujo artillería, no se atrevieron, y que la causa de no averse venido a Tarragona toda la gente principal uyendo a sido porqué luego les quemasen las casas y asolaran las haçiendas, que en esto no se perdona oy más que el primer dia». L'1 de novembre, seguien passant reusencs a Tarragona «uyendo de la tiranía de los franceses» (Diario: 209v. i 210). De com ho van passar de malament els reusencs que s'hi van quedar, ja en donem compte a l'apartat dels allotjaments.

\section{Ofensiva hispànica: Paret Delgada (gener de 1642)}

El 9 de desembre de 1641, els francesos abandonaven la vila, i el mateix 9 de desembre de 1641, els jurats enviaven un propi amb cartes per al marquès de la Hinojosa, el nou virrei en funcions (Güell, 2003: 185; Güell, 2001: 55-56) «en que avisan salió la gente y piden bamos o se les embie guarnición». Efectivament, l'endemà, dia 10, Hinojosa hi acudí amb la companyia de dragons i els jurats sortiren a rebre'l, li oferiren la vila i s'intercanviaren paraules d'ànim i de consol. Els hispànics no hi van deixar guarnició, de moment, però es restablí la comunicació i el trànsit habitual amb la ciutat de Tarragona (Diario: 247v., 248v. i 252v.).

Les autoritats catalanes de Barcelona de seguida van ser coneixedores d'aquesta nova situació. La Mothe escriví a Argençón i aquest estirà les orelles de Josep d'Urrea, agent de la vila a Barcelona, el qual degué demanar un gest als jurats. El dia 12 de desembre, els edils reusencs li enviaven el gest, una carta que no coneixem però que deduïm que devia tranquil-litzar els ànims, perquè Urrea l'anà a mostrar a tothom (els diputats, el Consell de Guerra, misser Josep Queralt, etc.). El Consell de Guerra els donà instruccions noves perquè resistissin els atacs dels hispànics, no els deixessin entrar i avisessin a La Mothe de qualsevol intent. Els asseguraven que només els podien sorprendre amb cavalleria i que, si es tancaven tots els portals, aquesta no podia fer cap mal ${ }^{31}$. Però això de la resistència no feia pels de Reus, i la vila es lliurà a Hinojosa la setmana següent. L'hispànic

31. Josep d'Urrea als jurats de Reus, Barcelona-Reus, 16 de desembre de 1641. ACBC, Fons municipal de Reus, Correspondència, 1601-1643, reg. 509/2, camisa 1641, núm. 329. 
només hagué d'amenaçar de dur mil soldats de cavalleria i passar la vila «ab lo rigor de la Guerra a foch i a sanch» per aconseguir el seu objectiu. Un trompeta que els envià els havia promès amnistia total, «no tocar a ningú en persona ni hisenda y sustentarà los privilegis, pràtigues, usos i consuetuts y no usarà de ninguna hostelitat», i el mateix Hinojosa els ho confirmà entrant sol amb tres o quatre cavallers dins de la vila. Els jurats van intentar avisar La Mothe o Lluís de Rajadell, inútilment, i es van trobar desesperats: «No sabem aont demanar socorro. Vejem lo exèrcit del rey d.Espanya lo strago han fet en la vila de Alcover per avernos o relatat personas de la matexa vila, vejem esta vila sens homens, sens monisions, sens armes, que las poques que tenien las tenen los soldats que la vila té en servei de la provínsia en la vila de la Selva». Així les coses, el 21 de desembre de 1641, el Consell General resolgué «sens oir que ningú contradís, que puix veiem que no teniem resistència alguna, que.ns rendirem al Rei d.Espanya i que se anàs $a b$ molta diligència a prestar la obediència a Tarragona $»^{32}$. Dit i fet. I els de Barcelona, enganyats, prometien, el dia 23 , ajut «a eyxa vila ab tot lo que convinga, pues o mereix sa fidelitat $»^{33}$.

El dia 27 següent, es renovaven els càrrecs consistorials, i els elegits per insaculació per detentar els principals càrrecs governatius van ser els membres de l'oligarquia local més significats del bàndol hispànic, per tal com resultaren nomenats jurats el doctor Cosme Anguera ${ }^{34}$, Pere Baldrich i Rafel Llorenç $c^{35}$ (el primer i el tercer assoliren categoria nobiliària en base als serveis prestats $\left.{ }^{36}\right) \mathrm{i}$

32. ACBC, Fons municipal de Reus, Acords, 1636-1673, reg. 12, f. 203-204 (Bofarull, 186: II, 18-20; Alentorn, 1931: 58-60; Maristany, 2003: 182-183).

33. Josep d'Urrea als jurats de Reus, Barcelona-Reus, 23 de desembre de 1641. ACBC, Fons municipal de Reus, Correspondència, 1601-1643, reg. 509/2, camisa 1641, s/n.

34. Anguera fou dels primers allistats per anar a la guerra de Salses el 1639 i l'any següent des de Barcelona i/o Tarragona féu d'enllaç del Consell avançant diners per cobrir diverses despeses. El 1641 estigué al setge de Tarragona i va ser qui signava els rebuts de la paga dels soldats de la companyia de la vila. L'any següent, fou elegit jurat en cap, però hagué d'abandonar Reus i passar a Tarragona acomboiant la diàspora hispànica reusenca, on es convertí en el factor principal dels reusencs. Allí gestionà l'obtenció de certificacions de les autoritats hispàniques per demanar el favor reial per a Reus i per a ell mateix, en les quals s'especificaven els serveis prestats acudint a guarir malalts a l'hospital, però sobretot proporcionant valuosos avisos a l'exèrcit hispànic i exhortant els seus convilatans a unir-se a la causa de Felip III. Hinojosa se'n serví per a missions d'espionatge. La seva hisenda de Reus fou cremada i confiscada, i ell mateix caigué presoner dels francesos i hagué de satisfer un rescat de 300 escuts i sofrir maltractaments. El 1643, aspirava a ser designat successor del protomedicat de Catalunya. Tornaria a ser jurat en cap de Reus l'any 1647. ACBC, «Guerras contra Francia», lligall 1542-1640, núm. 54 i lligall 1641-1704, s/n., Correspondència, 1601-1643, reg. 509/2, camisa 1643; Acords, 1636-1673, reg. 12, f. 314; Arxiu de la Corona d'Aragó [= ACA], Consell Suprem d'Aragó, lligall 292, 293 i 393 (Panno, 1993: 205).

35. Rafel Llorenç també actuà com a síndic de Reus i avançà quantitats de diners quan féu falta, prestà valuosos serveis al camp de Salses i, posteriorment, va ser capità de la companyia de Cambrils. El 1641, el veiem pagar les 15 lliures diàries d'allotjament a monsieur de Terraill. L'any 1648 fou elegit mostassà. Va morir cap al 1654. ACA, Consell Suprem d'Aragó, lligall 292; Manifiesto..., f. 3; ACBC, Fons municipal de Reus, Acords, 1636-1673, reg. 12, f. 332; AHA, Prioral de Sant Pere de Reus, òbits, 1639-1667, capsa 58, núm. 123, f. 181 (la novena).

36. El doctor Cosme Anguera obtingué privilegi de cavaller el setembre de 1643 i de militar el 1645. En una carta de febrer de 1646, ja emprava la preposició de abans del cognom. Llorenç també 
mostassà Rafel Fortuny ${ }^{37}$. La partida semblava guanyada per la causa hispànica. Hinojosa era, a més, un general amb carisme i sabé guanyar-se els reusencs. El dia 2 de gener de 1642, els visità i els prodigà mostes d'afecte i de consol que els reusencs agraïren tant que li asseguraren la seva «última resolución de defender la entrada al françés y miqueletes, peleando hasta morir» (Diario: 260). No tenien cap més remei, ja que, a Barcelona, havien descobert el doble joc i posaven la vila en el seu punt de mira. El dia 5 de gener de 1642, un trompeta provinent de Valls advertia que els francesos volien aplegar 3.000 infants, 500 cavalls i 8 peces d'artilleria, per tal «de hir sobre Reus y a de asolar el lugar y pasar la gente a cuchillo». Tres dies més tard, La Mothe arribava procedent del front de Lleida $\mathrm{i}$ feia el propòsit d'aplegar 6.000 infants i 1.000 cavalls per recuperar les poblacions passades al domini hispànic, també «de abrasar y destruir a Reus». No eren perspectives gaire galdoses per als reusencs, perquè es reconeixia que «deve dar cuidado porqué si a Reus no se embian mill ynfantes más lo que ay allí, estan perdidos y si se embian no podemos pelear en campaña con el enemigo» (Diario: 261v. i 264).

Els primers dies de 1642, Hinojosa tragué l'exèrcit de Tarragona i començà a expandir-se per tota la comarca. Va prendre Constantí, Altafulla, Tamarit, la Selva, Valls, el Pla, el Vendrell, Cabra, etc. Cap a mig mes, mesurava les seves forces amb les de Terraill, a Paret Delgada, feien taules (Alentorn, 1931; Güell, 2001). Per passar a l'Alt Camp, havia sojornat a Reus i havia allotjat l'exèrcit allí. En marxar, hi deixà una petita guarnició i els féu la promesa que hi acudiria al primer avís «aunque lo arriesgue todo», agraït que, a més dels allotjaments, la vila aplegués la milícia local i l'acompanyés en la incursió a Vilallonga que acabaria amb la topada de Paret Delgada. El 24 de gener, ho feren una trentena de milicians en l'assalt contra l'Aleixar i, a mitjan febrer, anaven al coll de Cabra (Diario: 281v.). Hinojosa reforçà la guarnició amb 800 homes $^{38}$ i els féu un gran favor en passar-los blat i recomanar la vila al virrei de València perquè facilitar-li l'adquisició d'una gran partida de gra a molt bon preu (i a compte dels 7.000 escuts que li havien pagat per a les fortificacions de Tarragona). En contraprestació, els reusencs enviaren als hispànics una gran quantitat de carros de transport $\mathrm{i}$ els cediren part de la collita de garrofes i vi ${ }^{39}$.

obtingué privilegi de cavaller a la mateixa data. Posteriorment, veiem el seu nom escrit a les actes del Consell amb la preposició de. ACA, Consell Suprem d'Aragó, 1ligall 292; ACBC, Fons municipal de Reus, Correspondència, 1601-1643, reg. 509/2, camisa 1646 (Anguera), i Acords, 1636-1673, reg. 12, f. 332 i 334 (Llorenç).

37. ACBC, Fons municipal de Reus, Acords, 1636-1673, reg. 12, f. 211. Fortuny també desenvolupà importants càrrecs governatius, entre els quals hi havia el de jurat en cap l'any 1641. El juliol de 1644 fou una de les tres persones que recomanava el governador Francisco de Toralto per al càrrec de recaptador de rendes eclesiàstiques en territori enemic. ACBC, Fons municipal de Reus, Acords, 1636-1673, reg. 12, f. 137; ACA, Consell Suprem d'Aragó, lligall 396.

38. ACBC, «Guerras contra Francia», lligall 1641-1704, s/n.; «Guerras contra Francia», 1 ligall 1641-1704, núm. 32 (Diario..., f. 267, 270 i 272).

39. ACBC, Fons municipal de Reus; Acords, 1636-1673, reg. 12, f. 214 (Diario..., f. 273). 


\section{Sant Celoni (28 de març de 1642)}

Dos mesos més tard, baixava el nou exèrcit que Felip III havia preparat a l'Aragó, sota comandament del marquès de Povar, s'ajuntava amb el de Tarragona i ho feia precisament a Reus. Això succeïa el 21 de febrer de 1642 i, fins que Povar no va marxar cap al nord un mes i escaig després, Reus es convertí en el seu sojorn habitual, per tal com no sofria estar prop d'Hinojosa, amb qui topà des del primer moment per qüestions puerils de comandament. Prèvia la marxa de Povar, els reusencs hagueren d'aplegar 40.000 racions de farina per al seu exèrcit (Diario: 282v., 283v., 295, 297, 298-299, 302v. i 303).

El 23 de març de 1642, el marquès de Povar iniciava la marxa al capdavant del seu exèrcit, marxa fatal que el duria a caure presoner amb totes les tropes a prop de Sant Celoni, els últims dies de mes (Sanabre, 1956; Relacion, 1642). La desfeta hispànica alterà la situació geoestratègica de la zona. La Mothe, victoriós, tornà a acaronar la idea de baixar sobre Reus aprofitant els pocs efectius de cavalleria de l'enemic (Diario: 308). Hinojosa només podia defensar Reus amb una escassa guarnició de 300 soldats (que, al cap d'una setmana, disminuí fins al centenar), i el primer dia d'abril, els envià a avisar de la magra situació, invitant els que volguessin (i s'haguessin significat més) a retirar-se a la protecció de la ciutat de Tarragona ${ }^{40}$. Es produí, llavors, un autèntic èxode de gent de Reus, encapçalat pel jurat en cap doctor Cosme Anguera, el més significat de tots els del partit hispànic, com consta a les certificacions que els comandaments de Felip III signaren posteriorment, «A los vecinos de Reus se avissó para que // se viniesen los que quisiesen a esta ciu[da]d, y se les an dado carros para traer la haçienda. Seran 10 o 12 los que an benido de los más principales, y todos los cónsules y demás oficiales de la cassa de la villa que eran los que corrían el mayor peligro. Otros se an hido a diferentes lugares». Havien d'emportar-se amb ells «toda la ropa, vino y aceyte que pudieren, porqué este lug[a]r es el que dicen an de asolar luego, que esta jente save castigar d-esta manera su reveldia» (Diario: 312-312v.).

Val a fer notar que, contràriament al que es podia suposar, la població de la vila no solament no disminuí, sinó que augmentà notablement. Efectivament, tot i l'exili forçat d'aquestes persones, els registres de baptismes assenyalen un nombre més elevat de naixements, de manera que si els quatre primers mesos de 1642 havien estat 17 (amb una població absoluta, en base al càlcul de la taxa de natalitat del 40\%o, d'uns 106 habitants), al llarg de la resta de l'any, van ser 9941, amb una població estimada d'uns 309 habitants. El canvi de mans a favor dels catalans i dels francesos comportà un augment poblacional del 300\%, o sigui, la vila multiplicà per tres els seus efectius demogràfics, cosa que mena a pensar que el partit hispànic, malgrat que fos el que s'imposava políticament, no era pas el de la majoria, sinó a l'inrevés.

40. ACBC, Fons municipal de Reus; Acords, 1636-1673, reg. 12, f. 224, Correspondència, 16011643, reg. 509/2, camisa 1642. La protecció de Reus es completava amb els 300 cavalls de guarnició a Vila-seca.

41. AHA, Prioral de Sant Pere de Reus, baptismes, 1633-1659, capsa 7, núm. 28. 
Reus quedà amb una guarnició escassa de 100 soldats, parapetats a l'església prioral de Sant Pere. Això era a mitjan abril de 1642, i el dia 23 del mateix mes les tropes franceses ja s'hi atansaven, i, després de ser repel-lides, es dedicaren a saquejar els ravals. El dia 7 de maig, se'n retiraven amb l'excusa que les represàlies franceses serien més grans si veien que la vila disposava de guarnició enemiga. Els francesos van entrar a Reus i s'hi van allotjar el 8 de maig de 1642 (Diario: 319v., 325v. i 333-333v. ${ }^{42}$. Entengueren que la fugida del grup de partidaris de Felip III era una purga prou important i en perdonaren la resta. L'endemà de la seva entrada, La Mothe expedia un ban pel qual manava, sota pena de la vida, a tota l'oficialitat i als capitans de miquelets, que no es maltractés cap vilatà ni se li toqués cap propietat, «antes los tingan per molt lleials vassallos» ${ }^{43}$. Els miquelets no els van fer gens de cas. De seguida que van poder, van robar unes mules a uns pagesos reusencs ${ }^{44}$. Ardena sortí a perseguir-los amb 25 cavalls, però la documentació no en dóna més detalls i tot fa pensar que els miquelets es feren escàpols a la muntanya i les mules no van tornar mai a Reus.

\section{Crèdit a la cort de Madrid}

Es va donar la coincidència que, precisament el dia 13 de maig de 1642, els síndics reusencs formalitzaven l'adquisició d'una important partida de blat (1.886 quarteres per un total de 5.476 lliures), en una complicada operació mercantil facilitada enormement per la recomanació dels hispànics! $!^{45}$. La comunicació amb Tarragona, a desgrat de les autoritats catalanes, va mantenir-se, de manera que els hispànics anaren rebent les notícies i les confidències públiques i notòries que corrien per Reus (Diario: 361v. i 364v.).

Durant l'estiu de 1642, en ple allotjament francès, els reusencs passaven, més que mai, pels més lleials servidors de la monarquia hispànica. Si, a Tarragona, tenien el doctor Cosme Anguera i, a Barcelona, el racional Josep d'Urrea, el seu valedor a la cort de Madrid era fra Francesc Roger, el qual tenia la porta oberta a les estances del totpoderós comte duc d'Olivares, a l'orella del qual xiuxiuejava:

[...] quant attenta era estada sempre aquexa vila a les cosas de son real servey, per lo qual fonc la primera $\mathrm{q}[\mathrm{ue}] \mathrm{ab}$ gust y presteza declarà son ànimo y se mostra ser estada sempre affecta a sa r[eia]l mag[esta]d, donant en assó gran exemple a las demés viles, perq[uè] fesen lo mateyx. I·m sé molt alegrat aja ella confirmat aquesta veritat proseïnt en totas sas accions tan honradament com ha proseit, q[ue]

42. La data d'entrada dels francesos també és avalada per un concís comentari als sacramentals quan, a la regesta d'enterrament d'un home de Montbrió, es comenta «y p[er] ser lo die entrà lo camp dels francesos, donà llicència per-a...». AHA, Prioral de Sant Pere de Reus, òbits, 16391667, capsa 58, núm. 123.

43. ACBC, Fons municipal de Reus, Correspondència, 1601-1643, reg. 509/2, camisa 1642. Maristany cita una part del ban, però ho fa fora de context, en l'ocupació de 1641, quan, en realitat, corresponia a la de l'any següent (Maristany, 2003: 179).

44. Josep d'Urrea als jurats de Reus, Barcelona-Reus, 13 de juny de 1642. ACBC, «Guerras contra Francia», lligall 1641-1704, núm. 33.

45. ACBC, Fons municipal de Reus, Correspondència, 1643-1691, reg. 1.897. 
per así a fet ruido la llealtat y fineza de aqueixa vila, y tinc per cert alcansarà de sa mag[esta]d tot lo que prudentment serà servida de demanar en son favor. Per lo qual [...] procuraran obtenir dels cabos del exèrcit certificacions dels serveys fets a sa mag[esta]d y del q[uè] ha patit en azienda y personas per ser li estada affecte ${ }^{46}$.

Fra Roger també es movia entre els principals ministres de la monarquia, i advertia els reusencs que «me apar q[ue] en la forma que.s parla de aqueixa vila resta ben acreditada, com és raó». Si a la cort de Madrid rebien (i s'empassaven) notícies com aquestes, on la realitat parava a les Antípodes, no ens ha d'estranyar que la monarquia de Felip III trontollés tan perillosament durant aquella dècada. Amb tot, els reusencs posaren fil a l'agulla a través del doctor Anguera, que era a Tarragona, el qual es va moure per aconseguir certificacions de serveis prestats a tall de cartes de recomanació dels principals comandaments hispànics (de mestre de camp en amunt). És per això que en trobem un bé de Déu entre la documentació $^{47}$, la majoria amb un text que es repeteix de l'una a l'altra, perquè probablement eren obra i gràcia de l'inefable Anguera, qui, d'altra banda, no va tenir inconvenient de pagar-les ${ }^{48}$. Hi ha les del marquès de la Hinojosa (20 de juliol), el baró de Seebach (26 d'agost), el marquès de Torrecuso (26 d'agost), Álvaro de Quiñones (27 d'agost), Antonio Gandolfo (27 d'agost), Rodrigo de Herrera y Céspedes (28 d'agost), etc.

En el moment que la vila tornava a ser dins de l'òrbita hispànica, ens trobem que, a la sessió de 28 de setembre de 1642, havien de reposar fins a 25 consellers que faltaven del total de 100 que tenia el Consell ${ }^{49}$. Són el doble dels 10 o 12 significats amb la causa hispànica que s'exiliaren a Tarragona a principis d'abril, si suposem que tots eren consellers.

La col-laboració de Reus amb les autoritats hispàniques de Tarragona fou fluida i sense reserves, i d'això se'n servirien els diversos governadors d'aquella plaça. Així, el 10 d'octubre de 1642, Juan de Arce els demanava carros i cavalcadures per transportar la pedra de les obres de fortificació de la ciutat ${ }^{50}$.

\section{Navegant entre dues aigües}

Això era difícil d'explicar a Barcelona, sempre atenta als moviments de les grans poblacions. El 20 de novembre de 1642, Urrea explicava als jurats la forta discussió mantinguda amb Josep de Margarit, al qual va intentar fer entendre que la situació l'havien provocat alguns elements «dolents» de la vila. Però l'astut Mar-

46. Fra Francesc Roger als jurats de Reus, Madrid-Reus, 6 de juliol de 1642. ACBC, Fons municipal de Reus, Correspondència, 1601-1643, reg. 509/2, camisa 1642.

47. Al fons de l'ACBC, «Guerras contra Francia», lligall 1641-1704 (Maristany, 2003: 184).

48. Trobem un rebut de 56 lliures del Dr. Anguera, per «presents y estrenes de segretaris per alcansar las certificatòries que té la vila per abono al rey de Espanya». ACBC, «Guerras contra Francia», lligall 1641-1704.

49. ACBC, Fons municipal de Reus, Acords, 1636-1673, reg. 12, f. 227-228.

50. Juan de Arce als jurats de Reus, Tarragona-Reus, 10 d'octubre de 1642. ACBC, Fons municipal de Reus, Correspondència, 1601-1643, reg. 509/2, camisa 1642. 
garit no es va deixar ensarronar i acabà cridant-li, enfurismat: «encara no volen que no·i aja algú si no que tots som sants, sens duda que si·s va allà a fer ynformació no·s trobarà ningun dolent». Urrea apuntava: «tot asó ha dit p[er] a que $\mathrm{v}$ [ostres] $\mathrm{m}$ [ercè]s estigan advertits ${ }^{51}$. A mitjan desembre de 1642, Reus feia tuf de deslleial a la terra i Urrea envià als jurats un propi per advertir-los seriosament: «enojat està lo s[enyo]r virrey contra d-ella y altras cosas, y lo perill que té de algun gran càstich». Els recomanava que enviessin síndics a prestar obediència al virrei francès «com o an fet altres llochs, y se a reparat molt com los de Reus no·y són vinguts», i fins i tot es permetia recomanar-los alguns noms de personatges del grat del virrei i que no s'estiguessin «en lo gasto que convé p[er] remediar-o en temps, y no després que no y aja remey» ${ }^{52}$.

L'avís causà efecte $\mathrm{i}$ els jurats enviaren ràpidament hàbils síndics a resoldre la situació. I se'n sortiren. Només quatre dies més tard de la missiva d'Urrea, els escrivia el president de la Generalitat, Bernat de Cardona, en un to complagut i comprensiu, ja que «per la de v[ostre]s m[ercè]s y sos síndichs havem vist lo stat de las cosas en eixa vila, hi·ns condolem molt de sos traballs» ${ }^{53}$. Només dos dies després d'aquesta missiva, el governador hispànic Juan de Arce els felicitava les Pasquies i es mostrava tan satisfet dels serveis que li havien prestat els jurats que demanava que fossin reelegides les mateixes persones ${ }^{54}$. Del que no hi ha dubte és que els reusencs tenien els més hàbils diplomàtics del país, capaços de tenir enganyats els uns (la cort de Madrid) i els altres (la Generalitat a Barcelona), i estar bé amb tothom, sense mullar-se per cap bàndol en concret, si la vila no era ocupada militarment i, a més, traient-ne tot el profit polític (certificacions), econòmic (blat) i militar (persecució de miquelets), segons el cas.

En una data indeterminada de 1642 que nosaltres situem pels volts de finals d'any, un carreter fill de la vila topà, a Cambrils, amb un La Mothe també força enganyat, que li preguntà pels seus amics de Reus. El carreter quedà del tot sorprès per l'efusivitat del mariscal virrei:

[...] li respongué tots estavem al servei de sa acselènsia i q[u]e los q[u]e avui governaven la vila i estaven dins d'ella tost moririan en servei de sa acsalènsia $i$ per lo rei crastianissim. En lo punt me preng[u]é las mans y me abrasà i $\cdot m$ manà $\mathrm{q}[\mathrm{u}$ ] jo ascrigués a v[ostres] $\mathrm{m}$ [escè]s agraïnt-los la bona diligència dels car[r]os del vi i pa, i qu·els aserigés q[u].els farà qualsevol mersè sols per mon respecte $\mathrm{i}$ $\mathrm{q}[\mathrm{u}] \mathrm{e}$ jo comendés tot so q[u]e voldrà per los de Reus, i asó dig[u]é devant de més de sinquanta mossurs y gent de la terra ${ }^{55}$.

51. Josep d'Urrea als jurats de Reus, Barcelona-Reus, 20 de novembre de 1642. ACBC, Fons municipal de Reus, Correspondència, 1601-1643, reg. 509/2, camisa 1642.

52. Josep d'Urrea als jurats de Reus, Barcelona-Reus, 18 de desembre de 1642. ACBC, Fons municipal de Reus, Correspondència, 1601-1643, reg. 509/2, camisa 1642.

53. Bernat de Cardona als jurats de Reus, Barcelona-Reus, 22 de desembre de 1642. ACBC, Fons municipal de Reus, Correspondència, 1601-1643, reg. 509/2, camisa 1642.

54. Juan de Arce als jurats de Reus, Tarragona-Reus, 24 de desembre de 1642. ACBC, Fons municipal de Reus, Correspondència, 1601-1643, reg. 509/2, camisa 1642.

55. Benet Bosch als jurats de Reus, Cambrils-Reus, 24 de..., de 1642. ACBC, Fons municipal de Reus, Correspondència, 1601-1643, reg. 509/2, camisa 1642. 


\section{Tempesta per la part de Barcelona}

Al tombant de 1643, el problema principal dels reusencs eren els miquelets, que els assaltaven i els prenien atzembles i cavalcadures. Pel governador Juan de Arce: «El remedio hera que v[uestras] $m$ [ercede]s se juntaran y se defendieran ${ }^{56}$, o sigui, que s'espavilessin ells mateixos. Aquell any, les servituds i la comunicació amb els hispànics de Tarragona devien ser tantes i tan fluides que, a les autoritats de Barcelona, els pujà la mosca al nas. Era difícil mantenir una situació de desinformació durant gaire temps. La gent es traslladava i parlava, i cada cop devia ser més públic i notori el veritable context en què es movien els de Reus.

Josep d'Urrea hagué de fer equilibris ben difícils i suportar una nova discussió amb el governador general Josep de Margarit (d'altra banda, bon amic seu). Sabien que Arce havia reclamat carros de transport i terrelloners per a les obres de fortificació de Tarragona i Urrea podia dir ben alt que Reus no n'hi havia donat (aquesta vegada!). L'objectiu dels reusencs era aconseguir passaports de pas del virrei per tal de poder-se moure per la comarca lliurement i desenvolupar un comerç de subsistència. A La Mothe no li feia gens de gràcia expedir aquests passaports (prou motius devia tenir...) i Urrea trobà el seu entorn bastant fred. Acudí al regent Fontanella, el qual el rebé «en satisfaçió de que no havia eixa vila donat ningun terralloner $\mathrm{p}[\mathrm{er}]$ a Tarragona, però que ya no·y havie que tractar-ne més». Josep d'Urrea es va permetre d'amenaçar el regent, amb el perill de trencar relacions amb Barcelona, «que si.s perdia dita vila, perdia lo General de drets que donava altre temps cada any, tres o quatre mil lliures». Fontanella entrà a parlar amb La Mothe, mentre Urrea esperava fora del despatx virregnal (suposem que amb una orella enganxada a la porta). Llavors aparegué Margarit $i$, en preguntar-li per quina causa hi anava (i per compte de qui), s'enredaren en una nova discussió: «i parlarem llarg i-ns donarem de les hastes bravament, de manera que.1 trobí molt terco també ab las cosas deyxa vila, y·m digué que may li havien complit cosa de les que li havien promés, hans bé, li havian fet eyxir los colors a la cara mes de dos vegades». Però valent-se de la seva amistat, Urrea li va suplicar que l'ajudés amb la qüestió dels passaports. Tot seguit, entraren dins del despatx del virrei, el qual es negà a expedir-li els passaports al-legant que era competència del Consell de Guerra: «Repliquí dient-li que-s apiadàs de aqueyx pobre lloch, que morian de fan, y que no o havien de pagar los bons p[er] los mals. Digue'm "esta tots son mals". Digue-li: "Mire V[ostra] Ex[cel-lènci]a que ni·a molts de bons y q[ue] per ser-o stats, en traure los jurats que haviam trets, lo s[enyo]r don Juan de Arze los volia mal de mort y p[er] so no.ls volia ni per son diner donarlos tampoch víveres"». Efectivament, possiblement per acontentar les autoritats catalanes, de cara a l'exercici de 1643, va sortir elegit un consistori afí encapçalat pel jurat en cap Llorenç Enveja, a qui Urrea havia recomanat fer síndic per visitar el virrei en els pitjors moments. Enveja tenia un nebot homònim, que era doctor

56. Juan de Arce al Dr. Cosme Anguera, Tarragona-Reus, 5 de gener de 1643. ACBC, Fons municipal de Reus, Correspondència, 1601-1643, reg. 509/2, camisa 1643. 
en dret i residia a la capital catalana. Amb tot, al final de la jornada, Urrea se n'anà amb les mans buides ${ }^{57}$.

A mitjan març de 1643, la situació amb Barcelona era d'una tensió tan extrema que el síndic que duia les cartes d'Urrea als jurats els confessava «que ell tremolava de tractar cosa d'eyxa vila ab sa Ex[cel-lènci]a». Però havien d'insistir en la qüestió dels passaports, ja que la vila s'hi jugava molt, i consultar alguna autoritat: «y·m tornà a dir que ell reparava molt parlar de aqueyxa vila, no perquè sa ex[cel·lènci]a los volgués mal, si no $\mathrm{p}$ [er] què sabia la gran comunicació tenian ab Tarragona. Yo li digué que sert fos que molt, si morian de fam». Era, doncs, impossible negar-ho, i Urrea, conscient, no ho feia, sinó que s'excusava en la necessitat de subsistir, però amb això no n'hi havia prou. El crèdit de les autoritats barcelonines semblava que s'havia esgotat: «No tinch més què dir, sinó lo molt que sento estas desditxas de ma pàtria y los treballs que tocan a tots, son mal nom, que $\mathrm{p}$ [er] més que.m canso en defensar-la no·u acabo sinó moltas moynas y disgusts que $\mathrm{m}$ costa, sens aprofitar, que és lo que més sento ${ }^{58}$. Acababa recomanant l'enviament de més síndics. La setmana següent, Urrea arrencà del regent, malgrat que el va trobar «algo enfadat de tant "Reus" (com digué)», sengles ordres per als caps militars de Prades i Cornudella, que ens imaginem que devien ser conduents a tallar els robatoris d'atzembles dels miquelets o a estrènyer-ne la persecució ${ }^{59}$.

El robatori de bestiar no solament anava a càrrec dels miquelets, sinó que els soldats hispànics també perpetraven robatoris sonats de tant en tant. El governador Juan de Arce ho va tallar de seguida, enèrgicament, ja que la majoria de soldats occits pels miquelets en accions aillades de «guerra menuda» eren els que s'apartaven de la unitat per anar a robar pel seu compte (Güell, en premsa) ${ }^{60}$. Va publicar un ban i va facultar els jurats reusencs per detenir els infractors i avisar els comandaments perquè anessin a buscar i se'n fessin càrrec. Amb còpia del ban, el soldat s'havia d'entregar sense oferir resistència, a pena de sis anys de galeres.

\section{El blat del governador Margarit}

Una nova qüestió vingué a pertorbar encara més les ja delicades relacions amb Barcelona, quan Josep de Margarit vengué als jurats de Reus una partida de blat que tenia arraconada al seu feu de Vallespinosa ${ }^{61}$. Sembla que li van comunicar

57. Josep d'Urrea als jurats de Reus, Barcelona-Reus, 7 de març de 1643. ACBC, Fons municipal de Reus, Correspondència, 1601-1643, reg. 509/2, camisa 1643.

58. Josep d'Urrea als jurats de Reus, Barcelona-Reus, 14 de març de 1643. ACBC, Fons municipal de Reus, Correspondència, 1601-1643, reg. 509/2, camisa 1643.

59. Josep d'Urrea als jurats de Reus, Barcelona-Reus, 24 de març de 1643. ACBC, Fons municipal de Reus, Correspondència, 1601-1643, reg. 509/2, camisa 1643.

60. En la carta als jurats de Reus, admetia que els soldats delinquien «saliéndose de las tropas y alargándose con peligro de sus vidas». Juan de Arce als jurats de Reus, Tarragona-Reus, 27 d'abril de 1643. ACBC, Fons municipal de Reus, Correspondència, 1601-1643, reg. 509/2, camisa 1643.

61. La sèrie de cartes que en parlen van des del 15 de maig de 1643 fins al 5 de febrer de l'any següent. ACBC, Fons municipal de Reus, Correspondència, 1601-1643, reg. 509/2, camisa 1643. (Sobre Margarit i Vallespinosa, vegeu Carbonell, 2002, i Güell, 2011.) 
que la vila tenia necessitat «de grans per·a viurer» i, per fer-los favor, aconseguí del virrei La Mothe llicència per vendre'ls-en una partida. El 6 de maig de 1642, els envià com a delegat seu per tancar l'operació el Dr. Pere Morell, capità de miquelets. El dia 2 de juny, el contracte estava tancat i signat i Margarit els recordava que li devien diners i que havien de passar a buscar el blat. A finals d'aquell mes, la paciència del governador començava a esgotar-se, en dir als jurats «la admiratió me causa lo prosehir de v[ostre]s m[ercè]s» que ni pagaven, ni anaven a buscar el blat a Vallespinosa, i es lamentava que podia haver-lo venut a qualsevol altra vila amb diners comptants, i que, per haver-ho fet a Reus, ells li pagaven:

[...] ab eixa dilació [...] i gustar de car[r]egar-me eix dany y burlar-se de mi // del que pens no·ls he donat ocasió, ni que menos los pugue estar bé prossehir ab mi d'eixa manera, com los prech considerin ma justa raó y me avisen per lo portador de sos intents, desenganyant-los que lo blat per restar a son compte s.és deixat de vendrer y de valer-me jo dels diners. Y així, los protesto que si de prompte no·m avisen ab ell, n·e faré tot sentiment, valent-me de tot lo que serà permès, estimant-los no vullan donar ocasió de que tinga de arribar ha fer semblants prossehiments, puis serà mon major gust lo servir-los en totes ocasions. Y no.m passen més ab paraules que no·m satisfaré de ninguna!

En una nota al final, els proposava que paguessin el blat encara que aleshores no el necessitessin. Els jurats li van contestar els primers dies de juliol, argumentant problemes de liquiditat i que ja havien quedat amb Morell de pagar-lo a terminis i no pas tot alhora. A més d'això, la sessió del Consell que va debatre la qüestió semblava que vinculava aquell contracte de compra amb el fet «que se obririe lo pas per-a portar qualsevol provisions a esta vila y los naturals poder puiar a la muntania ${ }^{62}$. Fa la impressió que es tracta de la vella aspiració de la vila de disposar de la llicència de les autoritats (els passaports) per desplaçar-se a comerciar a l'interior.

A mitjan setembre, Urrea rebé una nova esbroncada del seu amic Margarit: «Trobi.l com sempre enujat, y al cap de moltes dares y tomares restarem que ell vol tot lo diner y no part [...] diu que v[ostres] m[ercè]s tenen moneda doble sempre que volen $\mathrm{p}$ [er] fer grangeries». Al final, tot fa pensar que van adquirir (i pagar) el blat per parts, ja que, entre d'altres problemes, Margarit no volia cobrar en «creuets o rals de vuit y la vila no.n tinga». El 6 de novembre de 1643, el Consell de la vila resolia demanar a censal la quantitat i liquidar el deute amb el governador del Principat ${ }^{63}$.

La darrera notícia que tenim sobre aquest afer ens porta al 5 de febrer de 1644, quan, en una carta als jurats, el Dr. Pere Morell els recrimina la seva actitud i els insta a satisfer-li la part del preu del blat que quedava pendent. Margarit li havia escrit «ab notable sentiment», i a ell «Apar-me té tanta raó que me admiro de la paciència a tingut, si bé en moltes ocasions e procurat moderar-lo ara jo no·m sento ànimo de suplicar-li se entretinga més». Els donava de termini per

62. ACBC, Fons municipal de Reus, Acords, 1636-1673, reg. 12, f. 245.

63. ACBC, Fons municipal de Reus, Acords, 1636-1673, reg. 12, f. 257. 
pagar la setmana següent, altrament: «se valdrà dels medis de justícia, y és una llàstima se aja de arribar a estos termes [...] y no lo tingan a burles [...] que segons veig està resolt de pagar[cobrar]-se allí a hont trobarà asienda dels de Reus» ${ }^{64}$.

I tanta que en tenia, de raó, el bon Margarit! El 21 de desembre de 1643, els jurats reusencs enviaven síndics a tancar el contracte de compra de 800 quarteres de blat que Francesc Palau, de Tarragona, els oferia a raó de 70 sous la quartera i, un mes després, el Consell enviava fins a quatre síndics a cercar i adquirir blat arreu del país ${ }^{65}$. De fretura, semblava que n'hi havia, però, pel que fos, el blat del governador Josep de Margarit no era prou bo!

\section{El segon setge de Tarragona (1644)}

Entrem al 1644 i la impressió que ens fa allò que interpretem de la documentació és que Reus es decantava bastant més cap al costat hispànic que no pas cap al català. A més de l'afer Margarit, una notícia en concret ens mena a pensar que els hispànics tenien el control dels òrgans judicials reusencs (i amb això creiem que també el domini de la vila). El jutge local havia sentenciat un miquelet (Jaume Grasses) a la pena capital i, per assegurar-se que no hi hauria sorpreses en l'execució a mitjan desembre de 1643, el governador de Tarragona, Francisco de Toralto y Aragón, destacà a Reus dos capitans, Luis Francés i Antoni Font, amb ordres d'assistir-hi i, cas que aparegués algun impediment d'última hora, de custodiar el pres fins a la plaça tarragonina, on segur que l'executarien puntualment, «porqué assí conbiene al servicio de su mag[esta]d» ${ }^{66}$.

Aquesta situació tornaria a canviar al llarg de l'estiu, quan es produí l'intent de La Mothe d'assaltar la plaça tarragonina. A mitjan agost, el Consell de Reus tornava a mobilitzar la milícia per destacar-la al nou setge i negociava amb el Dr. Morell l'aportació de 50 terrelloners, que, un mes després, hagué d'augmentar a $100^{67}$. No hi ha més notícies documentals (l'expugnació que van intentar els francesos fou per assalt i durà pocs dies), però amb aquesta queda clara la participació de la vila i la col·laboració amb els francesos, aquest cop, contra els hispànics.

\section{Recapitulació dels canvis de bàndol}

Fins a mitjan 1642, Reus escenificava i protocol-litzava els canvis de bàndol, però, a partir de la segona meitat d'aquell any, és molt difícil saber si la vila la controlaven els uns o els altres, ja que satisfeia tothom i els dos bàndols se'n servien indis-

64. Dr. Pere Morell als jurats de Reus, Montblanc-Reus, 5 de febrer de 1644. ACBC, Fons municipal de Reus, Correspondència, 1601-1643, reg. 509/2, camisa 1644.

65. ACBC, Fons municipal de Reus, Acords, 1636-1673, reg. 12, f. 260 i 264-265.

66. Francisco de Toralto de Aragón als jurats de Reus, Tarragona-Reus, 13 de desembre de 1643. ACBC, Fons municipal de Reus, Correspondència, 1601-1643, reg. 509/2, camisa 1643. Grasses fou sentenciat el 5 de setembre inculpat d'un seguit de robatoris (Acords, 1636-1673, reg. 12, f. 247). Era de Constantí i l'interès de les autoritats hispàniques devia derivar del fet que es podia tractar d'un miquelet.

67. ACBC, Fons municipal de Reus, Acords, 1636-1673, reg. 12, f. 275 i 277. 
tintament. Era una vila oberta, amb tots els efectes que això implicava. El Camp de Tarragona esdevingué «terra de ningú, a l'abast del primer exèrcit que hi arribava» (Maristany, 2003: 184). Només a l'estiu, entre els mesos de maig i agost, es podia precisar el domini francès formalitzat a través de durs allotjaments.

\begin{tabular}{|l|l|l|l|l|l|l|l|l|l|l|l|l|}
\hline & Gener & Febrer & Marc & Abril & Maig & Juny & Juliol & Agost & Setembre & Octubre & Novembre & Desembre \\
\hline 1640 & & & & & & & & & & & & \\
\hline 1641 & & & & & & & & & & & & \\
\hline 1642 & & & & & & & & & & & & \\
\hline 1643 & & & & & & & & & & & & \\
\hline 1644 & & & & & & & & & & & & \\
\hline
\end{tabular}

Domini hispànic;

Domini catalanofrancès;

Domini indefinit o ambigu.

A través d'aquesta exposició, podem precisar que la vila de Reus canvià de mans no menys de cinc cops durant els quatre primers anys de guerra:

- Primer. L'agost de 1640, quan les autoritats de Barcelona la involucraren en la dinàmica de resistència contra la invasió hispànica de l'exèrcit del marquès de Los Vélez. Reus col-laborà molt activament en la construcció de la fortalesa de Salou, i també comprant armes, reclutant lleves i allotjant tropes milicianes.

- Segon. A mitjan desembre de 1640, els jurats reusencs anaren a rendir la vila davant del marquès de Los Vélez, que era a Cambrils.

- Tercer. Els primers dies de maig, arribava la contraofensiva catalanofrancesa després de la victòria de Montjuïc, i un nombrós exèrcit s'instal-lava al Camp de Tarragona i bloquejava la capital en un setge terrible. Mentre aquest va durar, Reus hi va col-laborar amb una companyia de 100 soldats i l'aportació de bastiments per sustentar l'exèrcit, a més de tots els productes i els materials que li van ser requerits.

- Quart. El 9 de desembre de 1641, els francesos abandonaren el Camp de Tarragona i l'endemà mateix els reusencs van oferir la vila al marquès de la Hinojosa.

- Cinquè. Entre principis de maig i finals de juliol de 1642, consten documentalment els allotjaments francesos a la vila, cosa que equival, de grat o per força, a un nou canvi de bàndol.

\section{Els odiosos allotjaments}

Reus patí els allotjaments militars com les càrregues més enutjoses de totes les que podia comportar la guerra. En ser una vila gran, rica i populosa, esdevenia idònia per acollir i mantenir tropes. Com veurem, els reusencs no van poder defugir l'allotjament anual de tropes franceses i, en alguns casos, els allotjaments foren salvatges i força costosos. 
Els primers allotjaments generalitzats que van tenir les poblacions catalanes van ser després de la campanya de recuperació de la fortalesa de Salses. Ben entrat 1640, el síndic Pau Ferran ${ }^{68}$, destacat a Barcelona, seguia de prop aquest assumpte, amoïnat per la possibilitat que la vila pogués ser objecte d'allotjaments. Les cartes que enviava informant-ne els jurats conformen un testimoni de preocupació constant. Ja el febrer o el març, s'assabentava que el virrei comte de Santa Coloma havia resolt, juntament amb els assessors de la capitania general, allotjar 3.000 soldats al Camp de Tarragona, comesa que van encarregar a misser Martí, Lo Negre ${ }^{69}$. Ferran l'anà a trobar i, quan li ho hagué confirmat, li preguntà desesperat com esperaven allotjar soldats allí, «p[e]r què las universitats y particulars estan destruits». Lo Negre li respongué, sense immutar-se: «que me-n imaginàs qualsevol mal $\mathrm{p}[\mathrm{e}] \mathrm{r}$ què lo de Balbasas és lo que comanda la enfanteria, $\mathrm{i}$ entén la tenia sola de sustentar, i diguere $\mathrm{m}$ [isse]r Martí tantas llàstimas, que me·n baixí de son casa tan afligit com v[ostra]s m[ercè]s o estaran quan o miraran de prop». Seguia explicant com aquells dies estaven reunits d'urgència els diputats per una carta de Felip III on se'ls comminava a sustentar les tropes i pagar els salaris als militars, «no obstant las Constitucions i Capítols de Cort» ${ }^{70}$.

En una carta de 10 de març, els explicava que el doctor Jeroni Guerau li assegurà que, de moment, no hi havia «orde ni resolució de que ajan de anar aquí soldats de peu ni de cavall, si bé és veritat de que no estam sens algun perill, i avem de estar llastimats dels dañs, inquietuts i encontres nos poden venir segons las novas eren, que són tals i de tanta consideració que són bastants a obligarnos a fer pregàries secretas, perquè i a presagis tals que no tan solament Catalunya perilla de algun gran conflicte, p[er]ò Valènsia, Aragó i Castella està en los matexos perills». Assegurava, igualment, que el doctor Magarolas era a Urgell per rebre 2.000 cavalls i que «A Sigas an fet anar 1.200 soldats $\mathrm{p}[\mathrm{e}] \mathrm{r}$ què i enviaren una compania i no.ls volgueren alojar» ${ }^{71}$.

Dos dies més tard, saltaren totes les alarmes. Ferran acudí al Palau Reial i abordà 3 o 4 comissaris que hi sortien, els quals «me amostraren las ordes que tenien, que és los trànsits per a portar unas tropas de cavalls a Vilallonga, Vilaseca, Riudoms, Cambrils, Riudecañes». Estava cantat que Reus també hauria

68. Apotecari de Reus, era llavors jurat segon de la vila. Ferran estigué el 1639 entre els soldats que anaren a lluitar a Salses, però el 2 de gener de 1640 era a Barcelona, on exercia de síndic i venia un censal de 780 lliures. Al mes de maig, era tornat a Reus, on s'ocupava de la distribució de farina i pa de munició. Ferran fou qui, el 5 de desembre de 1640, adquiria una important partida d'armes en comprar-la al General. Era mort a mitjan abril de 1641. ACBC, «Guerras contra Francia», núm. 54 i 42; Correspondència, 1643-1695, reg. 1.897; AHA, Parròquia de la Prioral de Sant Pere de Reus, òbits, 1639-1667, capsa 58, núm. 123.

69. També dit el Nyerro per haver estat un abrandat seguidor de Carles de Vilademany. Era escrivà de la Reial Audiència, des d'on passava avisos a la quadrilla dels bandolers Margarit. El febrer de 1627, el virrei l'empresonà quan un militar provinent de la cort l'inculpà de dirigir una quadrilla d'assaltadors de camins (Torres, 1991: 124; Dietari de Jeroni Pujades, 1976: IV, 83-84).

70. Pau Ferran als jurats de Reus. Barcelona-Reus, febrer o març de 1640. ACBC, Fons municipal de Reus, Correspondència, 1601-1643, reg. 509/2, camisa 1640, núm. 265.

71. Pau Ferran als jurats de Reus. Barcelona-Reus, 10 de març de 1640. ACBA, «Guerras contra Francia», núm. 33. 
d'allotjar l'exèrcit. Acudí a veure el doctor Guerau i el doctor Queralt, amb l'esperança de confirmar «que no bajen cavalls, cinó soldats de peu, i que lo número sie tant llimitat com sia posible». L'endemà, dia 13 de març de 1640, Ferran es deprimia encara més en confirmar l'allotjament de 3.000 soldats al Camp de Tarragona. Les notícies que donava del brogit en el qual s'havia convertit Barcelona (ciutat que també allotjaria, «cosa mai no vista!»): «Los brasos se aiuntan cada dia i no resolen cosa per ser lo cas tan difi[cul]tós i de tanta importànsia [...] La Diputació fa cada dia junta de 18 omens [...] fan enbaixadas al s[enyo]r virrei e no las reb ab molt gust. Tota Barcelona està confusa, tota va plena de síndichs de las universitats i no poden negotiar cosa, los advocats no consolan ningú; p[e]r las cosas del servei no la jà, sinó és que Déu lo done». Ferran mostrà una clarividència proverbial quan aconsellà els jurats de Reus que «p[er] amor de Déu, valégan-se de sa prudènsia, sin·s la tenen, que segons estan encaminades las cosas dupte de algun encontre». L'incansable Ferran aconseguí veure's amb el virrei el dia 14, a les cinc de la tarda, i li suplicà a favor de la vila, però Santa Coloma es limità a recomanar-lo a Lo Negre, que es comportaria amb moderació ${ }^{72}$.

A partir d'aquí, a través dels rebuts presentats al clavari pels prohoms i els vilatans que, en nom de la vila, acreditaven haver efectuat algun servei remunerat, podem recompondre els allotjaments que s'imposaren. Així, sabem que, entre maig i juny de 1640, allotjaren 19 companyies de valons, als caps de les quals hagueren de satisfer, el 8 de maig, un total de 531 lliures $^{73}$. Només que cada companyia estigués formada per un centenar de soldats, estem parlant de ben bé 2.000 militars que hi van estar allotjats durant dos mesos. Als primers senyals de la generalització de la revolta segadora, els valons degueren abandonar Reus a cuita-corrents i fer cap a l'Aragó.

\section{Allotjaments catalans}

A més dels allotjaments de tropes hispàniques, també n'hi hagué de milicians catalans (no encara francesos), i cal dir que, pel que sembla, van ser d'allò més respectuosos amb la llei i els pobladors. El 27 de setembre de 1640, Joan de Tamarit demanava a la vila que allotgés una tropa que els enviava, «q[ue] ja pagaran tot lo q[ue] gastaran ${ }^{74}$. A mitjan octubre següent, Savallà feia el mateix amb 200 milicians del terç de Vilafranca del Penedès, que acudien amb un jurat a la defensa de Cambrils, poble que no tenia infraestructura per acollir-los. Savallà especificava als jurats reusencs que aquell allotjament havia de ser «conforme lo que disposa la Constitució de Cataluña» ${ }^{75}$.

72. Pau Ferran als jurats de Reus. Barcelona-Reus, 12, 13 i 14 de març de 1640. ACBC, Fons municipal de Reus, Correspondència, 1601-1643, reg. 509/2, camisa 1640.

73. ACBC, «Guerras contra Francia», s/n.

74. Joan de Tamarit Lladernosa als jurats de Reus, Vila-seca?-Reus, 27 de setembre de 1640. ACBC, Fons municipal de Reus, Correspondència, 1601-1643, reg. 509/2, camisa 1640, s/n.

75. Comte de Savallà als jurats de Reus, Cambrils-Reus, 15 d'octubre de 1640. ACBC, Fons municipal de Reus, Correspondència, 1601-1643, reg. 509/2, camisa 1640, núm. 303. 
A més de milicians, a mitjan novembre, Reus també allotjà miquelets, o almenys això es dedueix dels rebuts que presentava el verguer Pere Martí del vi blanc que consumien ${ }^{76}$.

Durant el setge de Tarragona, Reus també allotjà, suposem que de manera ocasional, alguns soldats. Ho deduïm per rebuts com el que, amb data de 23 de juliol, presentava Joan Olives per 4 lliures «y són per lo servey y llits tinch fet en ma casa per orde dels señors dejurats als soldats» ${ }^{77}$.

\section{Allotjaments hispànics}

Després d'haver prestat l'obediència al marquès de Los Vélez, els reusencs van obrir les portes a la meitat de la cavalleria hispànica el dia 17 de desembre de 1640, la qual passà d'allotjar-se a Riudoms, a fer-ho a Reus. S'hi estaren exactament dues setmanes, ja que l'últim dia d'aquell mes rebia ordres de reprendre la marxa cap a Barcelona: «la vuelta de Larbós y la otra mitad a Vilanoba de Siches» (Diario: 11).

El 26 de gener de 1641, l'exèrcit hispànic del marquès de Los Vélez era derrotat davant de Barcelona, i perdia el bo i millor de la cavalleria i la iniciativa. Efectivament, d'ençà de la batalla, francesos i catalans organitzaren una fulminant contraofensiva que, malgrat que disposava d'efectius inferiors, va empènyer els hispànics ben avall, fins que va tancar-los literalment a Tarragona, a mitjan maig (Güell, 2003: 77 i s.). Entre febrer i maig, doncs, les viles del Camp de Tarragona hagueren de tornar a allotjar l'exèrcit hispànic. Segons el Memorial de 1666, a Reus s'hi va hostatjar el regiment del comte duc, 1.600 homes i 800 cavalls, que els costà 3.450 lliures i «la destrucción de mucha parte de árboles, olivares, y algarrovales del término» ${ }^{78}$.

El degotall de defuncions de soldats hispànics registrats al llibre d'òbits de l'església prioral de Sant Pere (molt més «llibreta de comptabilitat», que no pas «obituari» pròpiament dit) testimonien la recepció i l'acolliment dels ferits greus de la batalla de Montjuïc a l'hospital de Reus. Segons els volums sacramentals $^{79}$, són 192 els militars enterrats a Reus (el 17,7\% del total de difunts d'aquell any), i creiem que encara n'hi devia haver molts més. Una regesta del 9 de febrer diu: «En Reus sávado después de media noche, murió D. R[obert]o de Mendoça, alferez mayor de la Orden de Alcántara, y sobrino del arçob[is]po de Burgos. No quiso que le sangrassen ni haçer lo que los médicos ordenavan» (Diario: 32). Mendoza no apareix als sacramentals. Quants militars difunts més

76. ACBC, «Guerras contra Francia», núm. 19.

77. ACBC, «Guerras contra Francia», lligall 1641-1704, s/n.

78. Biblioteca de Catalunya [= BC], Fons de Reserva, Fullets Bonsoms [= F. Bons.], núm. 9.978, f. 2.3 (també Güell, 2003: 84). Idèntiques xifres a ACBC, «Guerras contra Francia», lligall de 1641-1704.

79. AHA, Parròquia de la Prioral de Sant Pere de Reus, òbits, 1639-1667, capsa 58, núm. 123. (Maristany, 2003: 178). Aquest autor dóna unes xifres netament superiors, per bé que cal advertir que és extremament fàcil confondre la barreja de regestes comptables que conté el volum (extremuncions, novenes, caps d'any, cossos presents, absoltes, processons, enterraments o simples deutes), quan s'intenta llegir a través de la bigarrada i penosíssima lletra de les anotacions. 
hi devia haver aquells dies que, per la causa que fos, no van registrar-se al volum sacramental? ${ }^{80}$.

Sabem exactament quants dies va durar aquest nou allotjament, foren vuitanta, des del 9 de febrer de 1641 fins al 29 d'abril del mateix any. Així consta a les regestes dels rebuts que els furriers del terç allotjat signaven ${ }^{81}$ a favor de Pere Miret, encarregat pel Consell de distribuir el pa de munició. Van ser un total de 126.160 racions. Comptant que la població catalana pogués vorejar el mig milió d'habitants (Simón, 1992), s'hauria pogut alimentar per un dia la quarta part del país! Arribaríem a la mateixa deducció a través dels rebuts o dels memorials «dels homens que tallen la llenya, començant a 19 de febrer de 1641» per als cossos de guàrdia, l'últim dels quals és precisament de 29 d'abril. I en aquesta data sortia de Reus Álvaro de Quiñones amb tota la cavalleria (pel que sembla, per no tornar-hi més), amb la intenció de socórrer Fernando de Ribera, a Valls (Diario: 57 ).

Aquests allotjaments hispànics foren continuats i ininterromputs malgrat que la tropa es renovés. Sembla que, a finals de març, sortia el terç del marquès de Los Vélez i entrava el terç d'irlandesos, 350 militars, amb dones i infants (més de 600) i 800 bagatges «y así donde llegan no ay langosta como ellos». Els havien tret de Vilallonga del Camp, on havien destrossat literalment la població, i en pocs dies feien el mateix a Reus, fins al punt que les mateixes autoritats hispàniques se'n van compadir i els van fer marxar «por el mucho daño que açen y aver sido este lugar siempre ovediente a su mag[esta]d y aver estado en él todos sus vecinos sin desampararle, y parece hera justo acelles buen passaje». Cambrils fou la nova destinació. Una localitat idònia, per tal com restava deserta i «por no aver paysanos importava poco que destruyeran el lugar». El 9 d'abril, tornaven a entrar els 800 homes del terç del marquès de Los Vélez (Diario: 37v.-38v. i 42v.-43).

Els hispànics s'hi tornaren a allotjar de manera intermitent i ocasional, per exemple: els primers dies de 1642, quan feia poques setmanes que havien marxat els francesos i el marquès de la Hinojosa preparava una incursió a Valls ${ }^{82}$, o els primers dies d'abril, quan els posaren una guarnició de 300 homes $^{83}$; també a finals de juliol, quan anaren a rebre el marquès de Torrecuso i allotjà la cavalleria dels Ordes Militars (Diario: 385v.), etc. Però es tractava d'allotjaments molt ocasionals i d'una durada ínfima.

\section{Allotjaments francesos}

Els pitjors allotjaments de tots van ser els perpetrats per les tropes franceses a partir de 1641, les quals no van tenir miraments amb una població que, fins que

80. Per banda francesa, bastants. Una relació de l'època diu que «A muy pocos de sus difuntos davâ Sacramentos, ni tierra sagrada», BC, F. Bons., núm. 7.689.

81. Juan de la Sierra, Francisco Berzarano, Lorenzo Pardo, Luis Ibáñez, Diego Lerin, Pedro de Taravilla, etc. ACBC, «Guerras contra Francia», lligall 1641-1704, s/n (Maristany, 2003: 178).

82. Foren molt pocs dies, abans del 15 de gener. ACBC, «Guerras contra Francia», lligall 1641$1704, \mathrm{~s} / \mathrm{n}$.

83. Marquès de la Hinojosa als jurats de Reus, Tarragona-Reus. ACBC, Fons municipal de Reus, Correspondència, 1601-1643, reg. 509/2, camisa 1642 (Diario: 312-312v.). 
hi van arribar, s'havia mantingut lleial a Felip III. Al principi, els reusencs van intentar subornar els comandaments per tal que s'allotgessin fora vila, oferint-los 50.000 rals. Els caps francesos els cobraren, però entraren a allotjar-se igualment dins la població, cosa que va provocar una brega amb els miquelets, i uns i altres s'esbatussaren pels carrers fins que es va determinar que els francesos s'hostatgessin als ravals i els miquelets, dins (Diario: 77v.-78). Quan fou l'època de sega, els francesos segaven pel seu compte, de manera que Francesc de Tamarit hi hagué d'enviar un escamot d'una dotzena de cavalls per protegir les feines del camp ${ }^{84}$.

Els reusencs en van quedat tan tips que, a principis de setembre de 1641, quan es llevà el setge de Tarragona i La Mothe s'endugué una bona part de l'exèrcit, no van voler admetre més allotjaments francesos, i preferiren condonar el servei pagant 900 ducats, però igualment baixà una tropa i allotjà 500 cavalls i uns quants membres de la infanteria (Diario: 172v. i 209). Segons el Manifiesto que hizo Tarragona... (Manifiesto, 1642), això va ser el 22 d'octubre de $1641^{85}$ i no en marxarien fins al 9 de desembre següent. Aquest imprès ens dibuixa un escenari dantesc amb situacions molt fortes. Algunes dades que hi consten es poden corroborar documentalment ${ }^{86}$. A més de diversos actes vandàlics perpetrats contra la imatgeria sacra local, els francesos van disposar que, en cada casa que s'allotgessin, hi hagués més soldats que naturals i que els patrons proporcionessin a cada un dotze unces de carn diàries i els festius la mateixa quantitat de peix, pa, vi, civada i garrofes. A més, van fer cos de guàrdia i armeria de la casa de la vila. El cap d'aquella trepa, monsieur de Terraill, s'adjudicà quatre cases de quatre dels principals prohoms de la vila (una de les quals era la de Miquel Valls, que havia estat la casa de la Diputació, on s'allotjava Tamarit quan sojornava a Reus) i cobrava als patrons 15 lliures diàries. «Las violencias contra las mujeres han sido infinitas», esmenta violacions, assassinats de donzelles i estupres (a Francesc Marca, que denuncià que els soldats allotjats a casa amenaçaven de violentar-li la filla, Terraill «ofreció por remedio que se la llevasse a casa, y solo él dormiria cô ella»), fins al punt que els reusencs van decidir dur totes les seves dones als convents «donde en quarto apartado y decente pudiesen aguardar el remedio del cielo» ${ }^{87}$. Els robatoris descarats estaven a l'ordre del dia: «El robar era à todas horas, machos, mulas, ropa, y quanto podia llegar a sus manos, y publicamente se ponian delante de los mismos dueños [...] Los dueños de las casas no se atrevian a salir dellas, porq. en saliendo se desaparecia quanto avian dexado en ellas, y los mismos se hâ desaparecido, pues son más de quatrocientas las q. oy estan perdidas, y pocas las puertas y ventanas q. ay en las que han quedado».

84. Francesc de Tamarit als jurats de Reus. Constantí-Reus, 21 de juny de 1641. ACBC, Fons municipal de Reus, Correspondència, 1601-1643, reg. 509/2, camisa 1641 (Maristany, 2003: 181).

85. Manifiesto, 1642. BC, F. Bons., núm. 7.689 [= Manifiesto...], f. 2. S'esmenta igualment a ACBC, «Guerras contra Francia», lligall 1641-1704, s/n.

86. Manifiesto, 1642: 2-3 (també Maristany, 2003: 181-182).

87. També ho esmenta el Diario (f. 211), en anotació del 31 d'octubre, que diu que el convent era el de Sant Francesc. És cert que els jurats reusencs se serviren del guardià d'aquest convent diverses vegades per tractar-hi qüestions delicades. 
Però els amos de les cases sí que en sortiren. Ho feren per abandonar Reus i escapar d'aquell malson. Segons un presoner francès que capturaren els hispànics: «avia desamparado la villa la más de la gente para huir del mal tratam[ien]to de los francesses y otros desatinos» (Diario: 228). Els registres de baptismes corresponents a aquells mesos ${ }^{88}$ confirmen plenament l'afirmació del dietarista: entre juliol i desembre de 1641, es produeixen únicament 10 baptismes (quantitat que contrasta amb la de la primera meitat d'any, que havien estat 127!), una ràtio de naixements que, sotmesa al càlcul de la taxa de natalitat del 40\%, donaria com a resultat una població de 41 habitants. Si atenem aquestes xifres, hem de pensar que Reus havia quedat pràcticament deserta.

Tots aquests desoris es produïen amb el consentiment (o la impotència) dels comandaments catalans, no dels de Barcelona, ja que Terraill restringí severament les comunicacions dels jurats amb la capital, de manera que el Consell hagué de consignar una partida per «propis segrets [...] per ço que lo S[eny]or de Terral avia dit no volia que escriguesen que no ves las cartas ${ }^{89}$.

Un interessant document de 1645 ens informa dels danys causats pels allotjaments francesos a la vila ${ }^{90}$. Per ell sabem que els allotjaments foren anuals, greus i terribles. Aquests de 1641 feren malbé tota la collita de blat, ordi i faves, com també la meitat de la verema, «que no·s pot precisar per ser tant gran lo dany» («En la huerta no han dexado arbol, ni planta verde...», deia el Manifiesto (1642)). Monsieur de Terraill obligà a donar menjar a tots els militars (les consabudes 12 unces diàries i 18 per als cavalls), mantenir-los i fer la vida als oficials majors (mitjançant un pagament de salari de 2 lliures i 10 sous o de 3 lliures diàries, segons el cas): «En dits alaugaments als qui no tenien per-a pagar lo gasto los trien de casa $\mathrm{p}$ [er] robar lo que tenien y donant los bastonades y fent-los tornar a ses cases $\mathrm{p}$ [er] fer lo gasto de tots los aliments».

L'any 1642, allotjà el mariscal La Mothe, com ja hem dit, a partir del dia 9 de maig. També llavors els francesos van fer malbé tota la collita de blat, ordi i faves, i obligaren els patrons a donar menjar als militars «y fent mal bé lo vi era $\mathrm{p}[\mathrm{er}]$ les cases [...] robant moltes cases y fen-na caura algunas cases y maltractant los patrons a bastonadas».

El 1643, allotjà el comte de Xabot, que també obligà a donar menjar als militars. Hi devien ser des de finals de maig, quan els reusencs se'n queixaven al governador del Principat Josep de Margarit i aquest els contestava el 2 de juny prometent-los suport davant del virrei. Hi van continuar el 5 de juliol, quan els consellers no podien celebrar junta «per tenir la gent de g[u]erra alaujada en dita vila» ${ }^{91}$. Aquell any ja s'havia recollit la collita, però feren malbé bona part de la verema i dels garro-

88. AHA, Parròquia de la Prioral de Sant Pere de Reus, Baptismes, 1633-1659, capsa 7, núm. 28.

89. ACBC, «Guerras contra Francia», lligall 1641-1704, s/n.

90. Memorial dels danys y exesos an fets la gent de guerra de nostron Rey Christianisim, que Déu guarde, en la vila de Reus, comensant en lo any de 1641 y proseguint fins la col[l]ita del p [rese] nt any de 1645... [= Memorial de 1645]. ACBC, «Guerras contra Francia», núm. 45 (també Maristany, 2003: 180, 183 i 184).

91. Josep de Biure y de Margarit als jurats de Reus, Barcelona-Reus, 2 de juny de 1643. ACBC, Fons municipal de Reus, Correspondència, 1601-1643, reg. 509/2, camisa 1643. 
fers. Segons s'explica, Xabot hi posà remei: «que és cert que si no fos estat lo señor compte de Xhabot tant bon cabo, se fora acabada de aquella vegada dita vila».

El 1644, allotjà monsieur de la Fondarella, però no podem precisar-ne les dates i només suposem que ho devia fer entre agost i setembre, amb motiu del segon setge de Tarragona. Com era costum en els francesos, forçaren els patrons a donar menjar a les tropes i feren malbé la meitat de la verema (que aquell any podia computar-se en unes 4.000 càrregues de vi).

El 1645, més del mateix: «que a no fos estat tenir en dita vila lo cabo que era musur de Sant Ones, que o ha fet molt bé, la aurian acabada d'esta vegada». Un dia que Saint-Aunèz s'absentà, hi hagué un altercat amb un patró i els soldats l'assassinaren impunement d'una estocada.

Al Memorial de 1645, queden pendents d'anotar-hi molts altres casos i excessos: «forçant dones y donselles y maltractan los de bastonadas als patrons, que $\mathrm{p}$ [er] ser tant grans los excessos no·s posen en lo p[rese]nt memorial». De fet, si tornem a mirar els llibres sacramentals de bateig i tornem a calcular la població en base a la taxa de natalitat del 40\%o, ens adonem que, dels 5.120 habitants que se li podrien suposar a la vila durant el quinquenni 1636-1640, es baixà, al següent, als 2.970. Reus havia perdut ben bé el $42 \%$ de la seva població aquests primers anys de guerra, i no normalitzaria els índexs demogràfics fins unes quantes dècades més tard.

\section{El cost}

Però, a més dels costos demogràfics, la vila hagué de suportar uns costos econòmics brutals. Els fronts oberts per on s'esmerçaren els cabals reusencs foren múltiples: lleves, allotjaments, lloguer de carros per fer transport, etc. Ja hem vist la despesa que li va resultar l'aventura de Salses, i també el que li va representar els allotjaments. Vegem-ne uns quants més.

\section{Les autoritats de Barcelona}

Com sol passar en època de crisi, les institucions polítiques del país, lluny d'ajudar, acaben d'escanyar els vassalls o administrats per tal d'aplegar diners i fer front institucional a la penúria. Els diversos organismes amb seu a Barcelona es van mostrar intransigents amb el daltabaix econòmic existent i van fer pagar milers de lliures als reusencs en uns moments d'allò més delicats.

El 24 de desembre de 1640, assabentats els diputats que els jurats havien prestat obediència al marquès de Los Vélez, davant de Cambrils, i entregada la vila a l'enemic, van comminar Antoni Miralles a dur-los 2.161 lliures que sabien que tenia per compte de la universitat reusenca, i van confiscar tots els comptes de particulars reusencs a la taula de canvis per un total de 4.353 lliures $^{92}$. El 20 de

92. ACBC, «Guerras contra Francia», lligall 1542-1640, núm. 51 i 55 (Maristany, 2003: 176-177). En una data indeterminada després de 1665 , els jurats reusencs van fer imprimir un memorial a la reina regent suplicant-li la devolució dels 21.610 rals (2.160 lliures) que havien estat sostrets i gastats, però mai retornats. 
març de 1641, el regent de la Reial Tresoreria forçava els jurats a satisfer 471 lliures «de les pensions que deviam als pobills Miret y Don Anton Cassador» ${ }^{93}$.

La contribució grossa va arribar a mitjan maig següent, en iniciar-se el setge de Tarragona, quan Joan de Tamarit Lladernosa demanava (d'aquella manera que no se li podia dir que no) una llista dels habitants més acabalats de la vila per tal que reunissin 8.000 lliures i les posessin a disposició de la Diputació del General, que les compraria a censal «perquè com ha fets tants grans gastos en esta Guerra per defensar la terra, està necesitada y per so demana que li deyxen a sensal dita cantitat» ${ }^{94}$. El Consell resolgué enviar mitja dotzena de síndics dels més acreditats (el Dr. Cosme Anguera, Josep Bofarull, Francesc Enveja, Joan Gras Sans, Pere Marca) a Barcelona, perquè cerquessin censals, mentre els jurats mirarien de rebaixar aquesta quantitat. El dia 7 de juny, no s'havia avançat gens. La Diputació els havia posat un termini de vuit dies i no quedava cap més remei que executar els veïns acabalats de la vila, per a la qual cosa formaren una comissió especial. El dia 22 de juny, els síndics de Reus creaven censal per les 8.000 lliures (400 lliures de pensió) a l'escrivania major de la taula de canvis, per cobrir el de la Diputació de 300.000 lliures. El febrer de 1643, el Consell consignava aquest censal a Antoni Miralles i enviava a Barcelona quatre prohoms (Llorenç Enveja, Francesc Canals, Pau Miret i Josep Bofarull) per tancar l'operació. L'any 1677 , aquest censal fou objecte d'un plet que encara era viu l'any $1803 !^{95}$.

El 19 d'octubre de 1641, veient la poca resistència i l'oposició nul·la de la vila envers els hispànics, el conseller terç Rossell els envià un comissari amb un notari per convocar-los a Valls, on els recriminà durament la «poca diligència ab expelir» unes tropes enemigues que s'havien atansat a la vila. De res no van servir les raons que els jurats van al·legar, Rossell els va imposar una multa de 2.000 ducats «a cada hu en particular» ${ }^{96}$.

\section{La fàbrica de Salou}

Acabar l'edificació de la fortalesa de Salou (d'altra banda, poca cosa més que una torre d'homenatge) (Florensa i Güell, 2005: 222-223) va implicar el pagament d'un munt de professionals de la construcció i el lloguer de molts carros, a més de llevar una dotació de la milícia i dur bastiments per mantenir tota aquella gernació. Entre el material documental, hi consten 38 rebuts corresponents a l'any 1640 (que van des del 31 de juliol fins al 29 de desembre), que importen 677 lliures. A més d'això, el Consell votà un ajut en metàl-lic d'entre 500 i un

93. ACBC, Fons municipal de Reus, Correspondència, 1643-1691, reg. 1.897.

94. Entre els «grans gastos» de la guerra hi havia les 40 càrregues de vi claret que demanaven que enviessin a Constantí, el preu del qual aniria a compte de les 8.000 lliures del censal. Francesc de Tamarit als jurats de Reus, Constantí-Reus, 6 de juny de 1641. ACBC, Fons municipal de Reus, Correspondència, 1601-1643, reg. 509/2, camisa 1641.

95. ACBC, Fons municipal de Reus, Acords, 1636-1673, reg. 12, f. 187-189 i 257 i 268; «Guerras contra Francia», lligall 1641-1704, núm. 1 (Maristany, 2003: 179). Sobre el censal de les 300.000 lliures, vegeu Serra, 1989.

96. ACBC, Fons municipal de Reus, Acords, 1636-1673, reg. 12, f. 198-199. 
miler de lliures al comptat, quantitat que encara no havia satisfet a principis d'octubre, quan Joan de Tamarit els la reclamava encaridament, ja que «sols aguardam esta oferta $\mathrm{p}[\mathrm{er}]$ posar-i mà». Tres dies més tard, els jurats enviaren a Salou 50 homes i 500 lliures, i també sindicaren quatre consellers per tal que venguessin censals i aconseguissin líquid ${ }^{97}$.

\section{Lleves}

A Salses, s'hi van trametre un total de quasi 190 homes, per bé que no tots hi van anar alhora. Pagaven el capità amb 50 lliures al mes, l'alferes amb 40, el sergent amb 12 i la resta amb una paga diària que oscil-lava entre els 4 i els 8 sous. Un càlcul aproximat del cost de l'expedició, només en els salaris dels milicians, puja més de 9.000 lliures $^{98}$. Segons assegurava el síndic Pau Ferran, foren més de 12.000 les lliures gastades en la campanya ${ }^{99}$. En canvi, el llibre major de clavaria del Consell reconeixia, el 24 de març de 1640, que es devien 7.585 lliures, 8 sous i 6 diners a diversos creditors que, al llarg de l'any 1639, havien presentat un total de 325 albarans «firmats y asentats en la llibreta per gastos ha fets la vila així p[e]r soldats com altras gastos ha fets la vila». Al compte, s'hi afegien 6.157 lliures i 2.409 lliures i 10 sous, sense especificar-hi res més que «per socorros dels soldats y d-estos demés sometents» ${ }^{100}$. Si ho hem de sumar tot, la xifra puja a 16.152 lliures, 6 sous i 6 diners, que és exactament la quantitat que apareix reiteradament en els memorials que la vila elevà després de la guerra a la cort de Madrid $^{101}$. Però és a través d'un altre memorial que sabem d'on sortien les quantitats que els jurats reusencs sumaven a les 7.585 lliures perquè en resultessin 16.152. Efectivament, el memorial imprès de 1666 al virrei per suplicar que tanqués la concòrdia als 42 creditors que tenia la vila, fa una triada entre: els 226 homes que anaren a Salses (no alhora, sinó en diverses etapes i substitucions) al llarg de 1639, més 16 bagatges, més els 50 soldats que van haver de reclutar durant tres mesos de $1638^{102}$.

97. ACBC, «Guerras contra Francia», lligall 1542-1640, núm. 43 «Cuentas y órdenes», i Joan de Tamarit Lladernosa als jurats de Reus, Tarragona-Reus, 4 d'octubre de 1640. ACBC, Fons municipal de Reus, Correspondència, 1601-1643, reg. 509/2, camisa 1640, núm. 312; Acords, 1636-1673, reg. 12, f. 162 i 163.

98. Comptant almenys set persones més de complement (els quatre caps d'esquadra, el pagador, el comptador, etc.), també a 12 lliures al mes, i una paga uniforme de 6 sous diaris per als 180 milicians restants, durant una campanya de cinc mesos tots plegats, dóna 9.270 lliures. Els salaris són els que apareixen a la Lista de tots los soldats que la universitat de la vila de Reus, a oufert a sa magestat (1640). ACBC, «Guerras contra Francia», lligall 1542-1640, núm. 51.

99. Pau Ferran als jurats de Reus, Barcelona-Reus, 14 de març de 1640. ACBC, Fons municipal de Reus, Correspondència, 1601-1643, reg. 509/2, núm. 255.

100. ACBC, «Guerras contra Francia», lligall 1542-1640, núm. 34.

101. Cas del memorial posterior a 1661. Memorial de la vila y particulars, que dirigeixen al Capità G[enera]l, manifestant-li que los gastos exorbitans que sofrí lo Comú per lo servei del Rey y de la peste són de 250.000 [= Memorial d.1661]. ACBC, «Guerras contra Francia», lligall 15421640 , núm 60, 6 a.

102. BC, F. Bons, 9.978. Sobre les lleves de 1638 i la campanya de Salses, vegeu igualment Maristany, 2003: 168-173 i 187. 
A finals de juliol, el temor a un atac corsari i l'exemple de moltes poblacions que havien aixecat la milícia féu que el Consell de Reus creés una estructura miliciana al capdamunt de la qual manaria un sergent major (Francesc Rovellat) i, per sota d'ell, quatre capitans (Pau Ferran, Francesc Salvador, Pere Miret i Josep Bofarull). Les confraries elegirien els alferes, els sergents i els caps d'esquadra, i dividirien la vila en quatre parts, cadascuna de les quals s'assignava a un capità $^{103}$. A finals de novembre, amb l'exèrcit hispànic a sobre, Reus tenia 60 homes a Salou i n'enviava 40 més cap a la Ribera d'Ebre (Bofarull, 1846: II, 15; Maristany, 2003: 174). Aquests últims van anar cap a Tivenys i hi van perdre tot l'equipament i les armes que duien. L'expedició i el material perdut elevaren el cost a les 672 lliures (Maristany, 2003: 188). Ja hem vist com, a mitjan desembre de 1640, aconseguia salvar in extremis els 700 milicians que havia tramès a defensar Cambrils.

Quan catalans i francesos estigueren sobre Tarragona, a partir de mitjan maig de 1641 , les autoritats de Barcelona van cridar tot el país a la mobilització general. Exigien un home per cada deu focs. Reus mobilitzà novament la seva companyia local de 100 soldats, la qual, pels rebuts del socors que se satisfeia als integrants (60 lliures diàries) trobats entre la documentació, va ser operativa (no sempre amb els mateixos efectius) del 28 de juny al 18 de desembre ${ }^{104}$. Van ser 173 dies a 60 lliures per dia, un total de 10.380 lliures.

Així que es llevà el setge i els francesos es replegaren del Camp de Tarragona, la mateixa milícia que els havia combatut s'afilerava a mitjan gener de $1642 \mathrm{amb}$ l'exèrcit hispànic per marxar sobre Vilallonga del Camp (i el 24 sobre l'Aleixar). El gest va commoure el propi marquès de la Hinojosa: «Esta ciud[ad] lo haçe lindamente pues saca un jurado d'ella toda la gente que puede conmigo, y los unos emos de ayudar a los otros». Un mes després, els hispànics passaven ordres per tal que «saliese también a juntarse con el exército la gente de Reus, menos 100 hombres, y la de Villaseca, menos 30/40», per marxar sobre el coll de Cabra ${ }^{105}$.

Això no va ser impediment perquè, a mitjan agost de 1644 , amb motiu del segon setge de Tarragona, el Consell es plegués a la demanda del Dr. Morell de «alguna compania de soldats que fés dit servei per la vila». Aquest cop no sembla l'ordeno y mando hispànic, de manera que els jurats enviaren síndics a allistar gent «del milor modo que pujen», pagant-los, és clar, un salari. També els enviaren terrelloners «pagats a gasto de las vilas», amb un bon salari de 6 sous diaris ${ }^{106}$.

\section{Armes i pertrets de guerra}

Reus, com moltes altres poblacions, es va armar, $\mathrm{i}$ ho va fer ràpid $\mathrm{i}$ malament. Sabem que, de l'aventura salsenca, en va restar un estoc d'arcabussos i de mos- 
quets considerable ${ }^{107}$ que van deixar tirats a Perpinyà (segurament perquè l'administrador de les deu mules que acompanyaven la milícia reusenca caigué malalt i restà postrat a l'hospital de Perpinyà) ${ }^{108}$; també que la vila disposava d'un munt d'armes blanques: llances, javelines o «xussos» ${ }^{109}$. No n'hi devia haver prou, perquè el jurat en cap i síndic, Pau Ferran, s'afanyà a adquirir una bona partida d'armes a la Diputació del General (32 arcabussos i 20 mosquets) per 417 lliures $^{110}$.

Hem col-leccionat tots els rebuts (23) que hem trobat sobre adquisició d'armes (compra o adobament) i pertrets (pólvora, corda i flascons) entre la documentació municipal reusenca. Abasten des del 22 de juny de 1640 fins al 20 de desembre del mateix any i sumen un total de pocs sous més de 416 lliures $^{111}$. Val a dir que la pólvora exigida per Joan de Tamarit a finals de setembre de 1640, la pagava la Diputació del General: «y no reparen tota la que vinga de prende-la $\mathrm{q}[\mathrm{ue}]$ jo la pagaré $\mathrm{q}[\mathrm{ue}]$ sian 1.000 càr[r]agas» ${ }^{112}$. Durant el període que durà el setge de Tarragona, n'hi ha cinc més, que pugen a 602 lliures $^{113}$.

\section{Carros i cavalcadures}

Per transportar els bagatges i els bastiments necessaris per mantenir la companyia de milicians destacada a Salses, els jurats disposaren de fins a deu cavalcadures que anaven a càrrec d'un administrador ${ }^{114}$. Durant la segona meitat de maig de 1640, s'hagueren d'emprar fins a 24 carros de la vila per dur soldats valons a Torredembarra. Es pagaven a raó de 12 rals el viatge, i si hem de fer cas dels rebuts trobats entre la documentació, la vila es gastà aquell mes més de 96 lliures. Entre la segona meitat d'octubre i la primera meitat de novembre següent, es van llogar cinc carros per dur homes i material a la fortalesa de Salou (20 lliures) ${ }^{115}$.

Ocupada Tarragona pel marquès de Los Vélez, i per tal de proporcionar transport a l'exèrcit hispànic camí de Barcelona, Reus resolgué (degudament instada a

107. 120 arcabussos i 25 mosquets, que van deixar en un racó del convent de Sant Francesc. Acabada la campanya militar, Fontanella els suplicava que se'ls enduguessin. Fontanella als jurats de Reus [Barcelona-Reus]. ACBC, Fons municipal de Reus, Correspondència, 1601-1643, reg. 509/2, camisa 1640, núm. 287.

108. Dr. Àngel Carrera als jurats de Reus, Perpinyà-Reus, 3 de gener de 1640. ACBC, Fons municipal de Reus, Correspondència, 1601-1643, reg. 509/2, camisa 1640, núm. 316 (Maristany, 2003: 172).

109. Centenars que el diputat Quintana, a falta de res més, reclamà. Josep Miquel Quintana als jurats de Reus, Ginestar-Reus, 4 d'octubre de 1640. ACBC, Fons municipal de Reus, Correspondència, 1601-1643, reg. 509/2, camisa 1640, núm. 308.

110. ACBC, «Guerras contra Francia», lligall 1641-1704, núm. 18 i 42.

111. ACBC, «Guerras contra Francia», lligall 1542-1640.

112. Joan de Tamarit Lladernosa als jurats de Reus. Tarragona-Reus, 30 de setembre de 1640. ACBC, Fons municipal de Reus, Correspondència, 1601-1643, reg. 509/2, camisa 1640, núm. 310.

113. ACBC, «Guerras contra Francia», lligall 1641-1704, núm. 18.

114. Bartomeu Ximenes, que els primers dies de febrer de 1640 havia caigut malalt a Perpinyà i no podia tornar. Dr. Àngel Carrera als jurats de Reus, Perpinyà-Reus, 3 de gener de 1640. ACBC, Fons municipal de Reus, Correspondència, 1601-1643, reg. 509/2, camisa 1640, núm. 316.

115. ACBC, «Guerras contra Francia», lligall 1542-1640. 
fer-ho) aportar vuit carros amb dues atzembles cada un, però el comissari Pau Gendre es va mostrar intransigent i féu pujar l'aportació a vint carros amb quatre atzembles i dos carreters cada un. Pere Baldrich fou nomenat síndic de la vila per acompanyar els carros, tenir-ne cura i cobrar els lloguers (28 rals diaris, tant si treballaven com si no, des del dia que abandonaven Reus fins al dia que hi retornaven). La vila es va comprometre davant dels propietaris a respondre si pel camí (o per accions de guerra) es perdia alguna atzembla, en cas que el monarca hispànic no en respongués, que era la cosa més probable ${ }^{116}$. En estimbar-se aquell exèrcit a Montjuïc hi va haver replegament general (per no dir fugida a la desbandada), creiem que aquests carros ho devien tenir molt difícil per tornar a casa indemnes.

Els carros que van quedar a la vila també van fer feina. El d'Antoni Nogués presentava, a finals de gener de 1641, un rebut de 260 lliures per dur garrofes a Tarragona, i el 24 de febrer següent, el compte dels carros que transportaven la llenya per als cossos de guàrdia sumava 75 lliures. Pere Baldrich seguí exercint de sotscomissari dels carros i era qui, al llarg de febrer, març i abril, presentà diversos rebuts pel lloguer dels carros de la vila, per 230 lliures, 220, $100 \mathrm{o}$ $400^{117}$.

Durant el setge catalano-francès de Tarragona, els carros reusencs es posaren al servei de la causa de la terra, per transportar material de setge, per fer arribar bescuit a Salou (31 de maig), per al transport de l'exèrcit (16 de juny) ${ }^{118}$, etc. Com era de suposar, quan els francesos abandonaren el Camp de Tarragona, els mateixos carros passaren al servei dels hispànics que eren a la plaça de Tarragona. Reus i moltes altres viles feren l'agost amb el manà tarragoní. Un plec de vint-i-quatre rebuts de l'any 1642 fa pujar fins a 534 lliures i 8 sous «los carros y azémilas y sustento de 400 soldados de la plaza de Tarragona [que] tenía d[ic]ha villa para su defensa» i el memorial imprès de 1666 diu que eren 8 carros, 32 atzembles i 16 carreters que van servir al front de Ponent (Lleida i Ribera d'Ebre), amb un cost de 3.000 lliures. Els primers dies de febrer de 1644, el governador de Tarragona agraïa als jurats els carros tramesos «que los dits carros tornaren a fer altra camí, puix diu seran pagats, $\mathrm{q}[\mathrm{u}] \mathrm{e}$ també $[\mathrm{h}] \mathrm{i}$ van los de Vilaçeca i altres vilas» ${ }^{119}$.

El Memorial posterior a 1661 avaluava en 48.000 lliures la despesa esmerçada entre 1642 i 1650 en concepte de bagatges i cavalcadures ${ }^{120}$, cosa que fa pensar que el pagament dels serveis de transport no va ser en efectiu (ni per imaginació!), sinó sobre el paper («mullat»).

116. ACBC, Fons municipal de Reus, Acords, 1636-1673, reg. 12, f. 184-185; «Guerras contra Francia», lligall 1542-1640 (Bofarull, 1846: II, 17).

117. ACBC, «Guerras contra Francia», lligall 1641-1704.

118. ACBC, «Guerras contra Francia», lligall 1641-1704, Correspondència, 1601-1643, reg. 509/2, camisa 1641.

119. ACBC, «Guerras contra Francia», lligall 1641-1704, núm. 15; BC, F. Bons., 9.978, Correspondència 1601-1643, reg. 509/2, camisa 1644.

120. Memorial d.1661. ACBC, «Guerras contra Francia», lligall 1542-1640, núm. 60, 6a. 


\section{Llenya}

La llenya per dur als cossos de guàrdia on s'allotjaven les tropes era, a més d'un servei que s'havia de prestar a l'exèrcit, una font de despeses, per tal com el Consell pagava els veïns que n'hi portaven. L'últim dia de 1640, Joan Gasol presentava rebut de 63 lliures «per una partida de llenya [...] per los cuerpos de guarda y espitals, tot del exèrcit del Rei, nostre S[enyo]r». El 1641, consten sengles memorials de febrer, març i abril dels homes llogats per tallar la llenya, que importaven 32, 26, 23 i 54 lliures, respectivament, pels quals sabem que el jornal del llenyataire computava a raó de 16 sous $^{121}$.

\section{L'hospital militar}

A mitjan maig de 1641, els catalans van decidir traslladar a Reus l'hospital de campanya que tenien establert a Barberà, a «la capella del Roser, que és fora los murs de aque[i]xa vila». Francesc de Tamarit comminà els jurats reusencs a assistir i ajudar en tot el Dr. Vidal, capellà major de l'exèrcit «y en tot cas faran una acapta per tota la vila aceptant flassades y altres cosas per los llits dels malalts». El 6 de juliol següent, el diputat militar els enviava dos caputxins recomanats «per confessar los malalts del hospital de $\mathrm{n}$ [ost]ro exèrcit y fer altras obras pías per lo sustento y regalo dels malalts. V[ostres] $\mathrm{m}$ [ercè]s se serviran fer lo gasto a dits dos religiosos caputxins, commodament, regalant-los en tot lo que poran, fent-los acomodar en una casa, per·a que·ls tracten com a religiosos y personas de vida exemplar».

Amb tot, no sembla que els jurats reusencs tinguessin gaire cura d'aquell establiment, almenys la manera d'administrar-lo no satisfeia prou les autoritats catalanes. La segona setmana d'agost, el visità el conseller terç de Barcelona, Pere Joan Rossell, i s'adonà de la manca de màrfegues i de llençols i que, a la vila, no havien fet l' «acapte» necessari per dotar-lo adequadament. Els rondinà enèrgicament, recordant-los que els havia encarregat la bona marxa de la casa «per-a que cuidassen y fosien protectors de aquell, y segons he vist v[ostres] $\mathrm{m}$ [ercè]s han cuidat d'ell des de las murallas y puig no han fet v[ostres] m[ercè]s lo que tenian obligació de fer, ni senyal, com si en dita vila no·y hagués charitat y tenir menester los dits soldats remey prompte de llits». Els ordenà cercar un centenar de matalassos i llençols, mal que fossin de préstec (ja que sabia «de certa sciència que aquí y ha molts matalassos»), i assignar una persona devota perquè en tingués cura. Si no ho feien, els amenaçava amb una multa d'un miler d'escuts, aplicadors a l'hospital «y ab assó entendran lo que no han volgut conèixer de la necessitat de dit hospital» ${ }^{122}$.

Sembla que, passat el setge i els allotjaments francesos, les autoritats catalanes establiren els equipaments hospitalaris de l'exèrcit a Santa Coloma de Queralt, més a l'esguard de l'interior del país. Alguna vegada hi duien soldats malalts

121. ACBC, «Guerras contra Francia», lligall 1542-1640 i lligall 1641-1704.

122. Francesc de Tamarit als jurats de Reus [Constantí-Reus], 14 de maig de 1641 i 6 de juliol de 1641 i Pere Joan Rossell als jurats de Reus, Constantí-Reus, 10 d'agost de 1641. ACBC, Fons municipal de Reus, Correspondència, 1601-1643, reg. 509/2, camisa 1641. 
des del Rourell ${ }^{123}$. El Memorial posterior a 1661 avalua en 1.400 lliures la despesa anual de manteniment de l'hospital ${ }^{124}$.

\section{Altres despeses}

A banda de la dinàmica militar, la vida civil reusenca es desenvolupava igual que sempre, amb una despesa que, ultra ser considerada «ordinària», no per això deixaria de sumar-se a les altres, la qual cosa augmentava considerablement la despesa general del Consell. El 25 de març de 1640, la vila signava la capitulació de la compra d'un pou de neu als frares cartoixans d'Escaladei, per un import de 454 lliures ${ }^{125}$.

Per complementar l'activitat militar, hi hagué una infinitat d'operacions que també van deixar rastre econòmic a la documentació. Entre finals de març i mitjan juliol de 1640, la vila contractà tots els treballadors locals que va poder (amb un salari de 4 sous diaris), perquè treballessin en l'adobament i la fortificació de les muralles, una obra que feien per trams i de la qual no excloïen ningú. Els comptes del segon semestre de 1641 importaven una despesa de 70 lliures ${ }^{126}$. A finals de juliol, s'adobaren diverses finestres, taules, portes i caixes a l'hospital de Sant Joan, al convent de Santa Anna i a la casa de la vila, per un total de 24 lliures i 15 sous $^{127}$.

També hi havia les despeses de representació (les grangeries a les quals es referia Josep de Margarit). Els jurats reusencs volien quedar bé com a amfitrions i, a mitjan setembre de 1640, quan van reunir-se amb Joan de Tamarit i el seu equip per anar a inspeccionar la fortalesa de Salou, li van fer festa grossa. Hi hagué tres pollastres, «3 gallines p[er] la olla», una bóta de vi, aiguardent, melindros, canyella, llimona, espècies i «garrafons de malvasia». Igualment, per complimentar el diputat reial Quintana, el 20 de setembre, se li va haver d'obsequiar, i a la recepció hi hagué gingebrons, melindros, «marçapans», bescuit del bo, confits, fruits secs del Camp, etc. El 6 d'octubre següent es va celebrar una altra recepció, aquest cop dedicada al conseller en cap de Barcelona, Pere Joan Calders, que era de passada per la vila. Van sortir a rebre'l «a cavall y los señors jurats en las gramalles vestits ab tota la honra que.s hague fet». El total d'aquestes reunions festives i recepcions oficials va comportar una despesa de quasi 33 lliures $^{128}$.

Una altra manera de quedar bé era complaure'ls en tot. L'1 d'octubre de 1640, Josep d'Ardena els reclamà tres cavalls amb els equips corresponents que

123. ACBC, «Guerras contra Francia», lligall 1641-1704.

124. Memorial d.1661. ACBC, «Guerras contra Francia», lligall 1542-1640, núm. 60, 6 a.

125. ACBC, Fons municipal de Reus, Correspondència, 1601-1643, reg. 509/2, camisa 1640, núm. 321.

126. ACBC, Fons municipal de Reus, Acords, 1636-1673, reg. 12, f. 147 i s. Un piquer presentava rebut el 24 de gener de 1641 de 4 lliures «per vint carretades de pedres que han presis per adobar las murallas de dita vila». «Guerras contra Francia», lligall 1641-1704.

127. ACBC, «Guerras contra Francia», lligall 1542-1640, núm. 1.

128. ACBC, «Guerras contra Francia», lligall 1542-1640, núm. 12 i 13; Acords, 1636-1673, reg. 12, f. 159 . 
eren de la seva companyia de cavalleria i, segons ell, uns fadrins de Reus havien sostret del campament. Sense poder esbrinar gaire més ni arribar al fons de la qüestió, els consellers reusencs li van pagar una composició de 100 lliures, «p[er] tres cavalls se perderen de la compania de dit gov[ernador] en lo terme de la $\mathrm{p}$ [rese]nt vila» ${ }^{129}$. Durant tot l'any de 1641 , el Consell pagà un parell o tres de mossos per tal que vigilessin la muralla dia i nit i en guardessin les portes. Els pagava a raó de 8 diners cada vespre, de manera que, en un mes, podien suposar més de 20 lliures $^{130}$ (240 a l'any). Semblen quantitats insignificants, però el cert és que tot anava sumant...

\section{Fallida municipal, rü̈na i endeutament crònic}

Ja l'any 1639, amb la campanya per recuperar la fortalesa de Salses, el Consell havia tocat fons (igual que la gran majoria de municipis catalans). Ingressava unes 4.500 lliures i n'havia de gastar quatre vegades més (16.152). La solució: augmentar els ingressos i endeutar-se. El Consell de Reus féu concessions noves d'exclusives i actualitzà les imposicions sobre venda al detall, va prohibir la venda a la menuda dels principals llegums, fruits secs i espècies. També donà en exclusiva la venda del tabac i de la pesca i els serveis d'hostatgeria, i a més regulà la venda de ferro obrat, cànem, fusta, porcs i sal. Al mateix temps, vengué censals per valor de quasi 6.000 lliures (negociats amb un interès del 4,5\% amb alguns dels prohoms de la vila: Josep Miró, Miquel Simó, Josep Pedret, etc.). La quota de pensió resultant d'aquesta nova càrrega censal (300 lliures anuals) només seria assumible amb l'augment d'algunes imposicions, de manera que apujà la lliura de carn i el dret de moltura. A la primeria de la guerra, els militars derrocaren el molí de Mascalbó (Maristany, 2003: 188 i 189).

El dia 22 de febrer de 1641, «la vila està posada en tants grans gastos per lo dels soldats y adobar murallas y altres gastos, que no basten diners». Un particular de Tarragona els oferia una partida de 2.000 quarteres de blat, i van haver d'assegurar l'operació amb els béns de la universitat ${ }^{131}$.

El 26 de gener de 1642, s'endevinava una carestia bladera considerable per «la estelaritat dels tems i cóm en lo Camp de Tarragona i en particular en lo terme de Reus, no ja blats ni ninguns grans sembrats p[er] a que los naturals i abitants de la vila pugan confiar de collita per a sestentar-nos». Hinojosa, que en rebia per mar, n'hi passà alguna quantitat, però, esgotada aquesta, el Consell envià síndics arreu a adquirir blat a censal, o sigui, endeutant-se. Aquell mateix dia havia passat un oficial a recollir tot de garrofes i vi per a l'exèrcit hispànic «y si no es Reus que dá todo lo que tiene, todos los demás reusan quanto pueden» ${ }^{132}$. Abans del

129. ACBC, Fons municipal de Reus, Acords, 1636-1673, reg. 12, f. 195 i «Guerras contra Francia», lligall 1641-1704.

130. ACBC, «Guerras contra Francia», lligall 1542-1640, núm. 19 i 24. El 3 de gener de 1641, sis individus presentaven rebut per 4 lliures i 10 sous «per aver guardat el portal de Robuster tres dies y una nit, cada un lo dia a raó quatre sous y la nit a raó tres sous».

131. ACBC, Fons municipal de Reus, Acords, 1636-1673, reg. 12, f. 186.

132. ACBC, Fons municipal de Reus, Acords, 1636-1673, reg. 12, f. 214, i Diario: 273. 
mes d'abril, els jurats Pere Baldrich i Pere Marca havien comprat farina per valor de més d'un miler de lliures, i al mes següent es tancava l'operació de compra de blat a València, a compte del donatiu que van haver de fer a les tropes de Felip III, blat que no entraria a la vila fins al 2 d'agost ${ }^{133}$.

Tanta despesa obligà les autoritats municipals a gravar un seguit de productes a 6 diners per lliura (mercaderies i càrregues de vi) ${ }^{134}$. Molts particulars de Reus, aprofitant la conjuntura politicomilitar, van deixar de pagar delmes a l'Església. L'octubre de 1642, quan els jurats demanaven un ajut al capítol de canonges de Tarragona, aquest, molt sibil-linament, els recordava que no hi podia acudir «per la concideració que tenim en las cobrances, puix devent-nos lo particular de aqueixa vila moltes cantitats de censos, escusam lo possible per no afligir ab nous treballs» ${ }^{135}$. Els últims dies de 1644, el Consell es quedà sense líquid, en haver de lluir un censal de 3.060 lliures als pares descalços de Barcelona ${ }^{136}$.

No anem més enllà d'aquest any, però consignem que els diversos memorials confegits tot just acabada la guerra parlaven de 250.000 lliures de «gastos exorbitans que sofrí lo Comú per lo servei del Rey y de la peste». Els comptables reusencs filaven molt prim i tenien memòria d'elefant. Per aquests sis primers anys de guerres (1639-1644), computaven una despesa de 61.982 lliures i asseguraven que els ingressos no depassaven les 4.500 lliures anuals, quan, en pensions de censals venuts, n'havien de cotitzar 5.600 ${ }^{137}$. Un altre memorial, també sense data, assegurava que el deute censal era de 108.006 lliures i suposava un càrrec anual de 5.400 lliures, al qual se n'hi havien d'afegir 2.600 de despesa corrent. S'havien carregat de censals «havent gastat aquells per occació de les tribulacions, contagis, esterilitats y la major part en servey de sa mag[esta]t desde la campanya de Salsas fins huy», i eren capaços d'aportar proves documentals de censals creats per un valor total de 200.000 lliures. El memorial s'annexava de documentació probatòria de la pobresa en què s'havia sumit la vila, la incapacitat d'arrossegar el deute censal, la concòrdia de creditors establerta i un decret reial d'una nova concòrdia auspiciada per la Reial Audiència ${ }^{138}$. Tots aquests memorials foren la conseqüència de les devaluacions monetàries dels anys 1653 i 1654 que van significar augmentar el deute un $200 \%$ (ja que, d'acord amb les pragmàtiques, s'havien de pagar «lliura per lliura»). El 1661, Francesc Baldrich estava sindicat per més de 60 viles del Camp de Tarragona, que, juntes, acumulaven un deute superior a les 200.000 lliures (Maristany, 2003: 194-195), i els anys següents, la universitat reusenca elaborava aquests memorials tan nombrosos $\mathrm{i}$ acurats com inútils.

133. ACBC, Fons municipal de Reus, Correspondència, 1643-1691, reg. 1.897; Acords, 1636-1673, reg. 12, f. 22 (Maristany, 2003: 189-190).

134. ACBC, Fons municipal de Reus, Acords, 1636-1673, reg. 12, f. 227-228.

135. Capítol de canonges de Tarragona als jurats de Reus, Tarragona-Reus, 8 d'octubre de 1642. ACBC, Fons municipal de Reus, Correspondència, 1601-1643, reg. 509/2, camisa 1642.

136. ACBC, Fons municipal de Reus, Acords, 1636-1673, reg. 12, f. 285.

137. Memorial d.1661.

138. Memorial del $q[u e]$ la huniversitat de Reus dedueix ab justificació de [...] Memorial donat a sa mag[esta]d. ACBC, Fons municipal de Reus, Correspondència, 1643-1691, reg. 1.897 (Maristany, 2003: 193-194). 


\section{Epíleg}

Malgrat els esforços de les autoritats reusenques per esquivar els estralls de la guerra, la frontera militar del Camp de Tarragona la involucrà en una espiral de misèries. Reus, com tantes altres poblacions, s'arruïnà, el Consell féu fallida i hagué de recórrer al concurs de creditors per atendre l'exorbitant i crònic endeutament contret al llarg d'aquells anys. Amb el comerç bloquejat, passà gana i va tenir prou feina a poder-se proveir de gra. La població sofrí duríssims allotjaments i a voltes abandonà la vila, que, en general, experimentà un descens demogràfic espantós. Ruïna, misèria, fam, desolació...

Però Reus va renéixer com l'ocell Fènix. Va remuntar des de les seves cendres fins que va ocupar una privilegiada posició al Camp de Tarragona. Al llarg del segle XVIII, es convertí en la «capital de l'aiguardent» i, quan esclatà la guerra del Francès, doblava Tarragona en població. És curiós que, en aquella ocasió en què Napoleó envaí el país durant sis anys (de 1808 a 1814), la situació (i l'actitud) tornà a ser calcada a la de mitjan segle XVII: resistència nul-la a l'invasor, col·laboracionisme total i absolut, i, al recer de la Tarragona devastada, nou floriment econòmic i augment poblacional notable mercès als refugiats. La història es tornava a repetir.

\section{Bibliografia}

AADD (1990). «Baralles i batalles entre Reus i Tarragona». Lligalls. Revista d'Història. Societat d'Estudis Històrics «Salvador Vilaseca». Reus, 1 (juny).

ALENTORN I BALLESTER, Francesc (1931). Els vallencs pel carrer de l'Amargura (La vila de Valls a través de la guerra de Separació). 1639-1660. Valls: Impremta Castells.

ANDREU, Jordi (1986). Economia i societat a Reus durant la crisi de l'Antic Règim. Reus: Associació d'Estudis Reusencs (Rosa de Reus; 65).

Bofarull y Brocì, Andrés de (1846). Anales históricos de Reus: Desde su fundacion hasta nuestros dias. II. Reus: Impremta Pedro Sabater.

Carbonell i Buades, Marià (2002). «Els barons de Vallespinosa». A: Anglès, Francesc i Huguet, Joan (eds.). Vallespinosa i el seu patrimoni monumental i artístic conservat (segles XII-XVIII). Tarragona: Diputació de Tarragona, 21-69.

CRistòfol i Escorsa, Pere (2011). «Les preses d'Àger durant la guerra dels Segadors». A Carn! [en línia], 17, 16-21. <www.acarn.cat>.

Dietari de Jeroni Pujades (1976), IV (1626-1630). Edició a cura de Josep M. Casas Homs. Barcelona: Fundació Salvador Vives Casajuana.

Florensa i Soler, Núria i GüEll, Manel (2005). «Pro Deo, pro rege et pro patria». La revolució catalana i la campanya militar de 1640 a les terres de Tarragona. Barcelona: Fundació Salvador Vives Casajuana / Òmnium.

Fort I Cogul, Eufemià (1975). Notícia històrica d'una singular institució medieval: La Comuna de pobles del Camp de Tarragona. Barcelona: Fundació Salvador Vives Casajuana.

Gual ViLÀ, Valentí (1993). La família moderna a la Conca de Barberà. Tarragona: Institut d'Estudis Tarraconenses Ramon Berenguer IV / Diputació de Tarragona.

GüELl, Manel (1996). «Aproximació a la resistència fiscal dels municipis catalans a la vetlla de la revolta dels Segadors: L'impost de fortificacions de 1639». A: Actes. III Congrés Internacional d'Història Local de Catalunya. Barcelona: L'Avenç, 241-256. 
—(2001). «Valls durant els primers anys de la guerra dels Segadors». Quaderns de Vilaпіи, 39, 47-69.

- (2003). El setge de Tarragona de 1641. Tarragona: Arola Editors.

- (2008). Camí a la revolta (1625-1640). Lleida: Universitat de Lleida (Josep Lladonosa; 9).

- (2011a). La crisi durant la guerra del Francès (1808-1814) al Camp de Tarragona. Tarragona: Cercle d'Estudis Històrics i Socials «Guillem Oliver» del Camp de Tarragona.

-(2011b). Els Margarit de Castell d'Empordà: Família, noblesa i patrimoni a l'època moderna. Barcelona: Fundació Noguera (Estudis; 56).

—(en premsa). «El Diario de las guerras de Cataluña por los años 1640, 1641 y 1642: Un dietari inèdit dels primers anys de la guerra de Separació al Camp de Tarragona (1640-1642)». Butlletí Arqueològic, RSAT, 34.

Jordà i Fernández, Antoni i Pujals i Vallvé, Joan M. (1983). Les lluites pel port de Salou: Un enfrontament singular entre el progrés econòmic i els drets senyorials. Tarragona: Institut d'Estudis Tarraconses Ramon Berenguer IV (Secció d'Arqueologia i Història; 49).

Manifiesto que hizo Tarragona, sobre persuadir al Principado sus quietudes (1642). Madrid: Catalina de Barrio y Angulo.

Maristany, Carles (2003). «Els segles Xvi i XviI». A: Anguera, Pere (dir.). Història General de Reus. Volum II: L’època moderna. Els segles XVI, XVII $i$ XVIII. Reus: Ajuntament de Reus.

Morell i Torrademè, Josep (1986). El port de Salou en el segle XVIII. Tarragona: Institut d'Estudis Tarraconenses Ramon Berenguer IV.

-(1993). Aproximació al comerç marítim de Reus i de Salou al segle XVIII. Barcelona: Fundació Salvador Vives i Casajuana.

Panno, Francesc-Pasqual de (1993). Motines de Cataluña. A cura d'Isabel Juncosa i Jordi Vidal. Barcelona: Curial.

Relacion de la derrota, y presa del general don Pedro de Aragón y de todo su exercito (1642). Barcelona: Gabriel Nogués.

Rovira i Gómez, Salvador; Anguera, Pere i Ventura i Solé, Daniel (1982). Gran Geografia Comarcal de Catalunya [= GGCC]. Volum VII: Tarragonès, Baix Camp, Alt Camp. Barcelona: Fundació Enciclopèdia Catalana.

SANABRE, Josep (1956). La acción de Francia en Cataluña en la pugna por la hegemonía de Europa (1640-1659). Barcelona: Real Academia de Buenas Letras.

Segarra i Blasco, Agustí (1988). L'economia de Reus al segle XVIII: El comerç de l'aiguardent. Reus: Centre de Lectura (Assaig; 24).

-(1994). Aiguardent i mercat a la Catalunya del segle XVIII. Vic / Reus: Eumo / Centre de Lectura (Referències; 17).

Serra, Eva (1988). «Notes sobre l'esforç català a la campanya de Salses. Juliol 1639, gener 1640». A: Homenatge al Doctor Sebastià García Martínez. II. València: Generalitat, 7-28.

Serra i Puig, Eva (1989). «L'inici formal de la guerra contra el rei: un censal de tres-centes mil lliures. Nota a un aspecte de la guerra dels Segadors». A: El barroc català: Actes de les jornades celebrades a Girona els dies 17, 18 i 19 de desembre de 1987. Barcelona: Quaderns Crema, 89-136.

Simón I TARrés, Antoni (1992). «La població catalana a l'època moderna. Síntesi i actualització». Manuscrits, 10, 217-258.

Torres I SANS, Xavier (1991). Els bandolers (s. XVI-XVII). Vic: Eumo. 